\title{
Fundamental Mechanistic Understanding of Electrocatalysis of Oxygen Reduction on Pt and Non-Pt Surfaces: Acid versus Alkaline Media
}

\author{
Nagappan Ramaswamy and Sanjeev Mukerjee \\ Laboratory for Electrochemical Advanced Power, Department of Chemistry and Chemical Biology, Center of \\ Renewable Energy Technology (NUCRET), Northeastern University, 360 Huntington Avenue, Boston, MA 02115, USA \\ Correspondence should be addressed to Sanjeev Mukerjee, s.mukerjee@neu.edu
}

Received 2 October 2011; Accepted 22 December 2011

Academic Editor: Milan M. Jaksic

Copyright (C 2012 N. Ramaswamy and S. Mukerjee. This is an open access article distributed under the Creative Commons Attribution License, which permits unrestricted use, distribution, and reproduction in any medium, provided the original work is properly cited.

\begin{abstract}
Complex electrochemical reactions such as Oxygen Reduction Reaction (ORR) involving multi-electron transfer is an electrocatalytic inner-sphere electron transfer process that exhibit strong dependence on the nature of the electrode surface. This criterion (along with required stability in acidic electrolytes) has largely limited ORR catalysts to the platinum-based surfaces. New evidence in alkaline media, discussed here, throws light on the involvement of surface-independent outer-sphere electron transfer component in the overall electrocatalytic process. This surface non-specificity gives rise to the possibility of using a wide-range of non-noble metal surfaces as electrode materials for ORR in alkaline media. However, this outer-sphere process predominantly leads only to peroxide intermediate as the final product. The importance of promoting the electrocatalytic inner-sphere electron transfer by facilitation of direct adsorption of molecular oxygen on the active site is emphasized by using pyrolyzed metal porphyrins as electrocatalysts. A comparison of ORR reaction mechanisms between acidic and alkaline conditions is elucidated here. The primary advantage of performing ORR in alkaline media is found to be the enhanced activation of the peroxide intermediate on the active site that enables the complete four-electron transfer. ORR reaction schemes involving both outer- and inner-sphere electron transfer mechanisms are proposed.
\end{abstract}

\section{Introduction}

Oxygen reduction reaction (ORR) on noble and nonnoble metal surfaces remains as one of the well-investigated electrochemical processes. While under acidic conditions Ptbased systems remain the mainstay as catalyst materials for ORR, in alkaline electrolyte a wide range of nonnoble metals and their oxides are stable enough for practical applications $[1,2]$. ORR pathway rather than ORR mechanism has typically been addressed in the literature due to the easy accessibility of the former from rotating ring-disk electrode (RRDE) studies, and the complexity in understanding the latter [3]. ORR pathway is found to be similar in both acid and alkaline media on Pt-based materials $[3,4]$. Based on the initial propositions by Damjanovic et al. [4-6], rate determining step $(r d s)$ on Pt electrodes is widely agreed to be the first electron transfer step to the adsorbed molecular $\mathrm{O}_{2}$ with or without rapid proton transfer [4-6]. A major alternative viewpoint to $r d s$ in ORR was proposed by Yeager et al. [7], wherein it was proposed that ORR on Pt surfaces is likely to involve dissociative chemisorption of molecular $\mathrm{O}_{2}$ with the initial adsorption of $\mathrm{O}_{2}$ (with or without an electron transfer) as the $r d s$. ORR on Pt-based catalysts is understood to proceed via "parallel" routes with the $4 \mathrm{e}^{-}$"direct" or "series" pathway as the predominant route and a minor route involving $2 \mathrm{e}^{-}$pathway to peroxide. Various kinetic models for ORR have been developed to understand the reaction pathways. The first model was developed by Damjanovic et al. [8] following which Wroblowa et al. [9], and Anastasijević et al. $[10,11]$, proposed extensive models.

For electrocatalytic reactions proceeding via inner-sphere electron transfer mechanism, it is typically assumed that 
either molecular adsorption of reactant species (dissociatively or nondissociatively) or an electron transfer is the first step [12]. For neutral, nonpolar species like molecular $\mathrm{O}_{2}$, direct molecular $\mathrm{O}_{2}$ adsorption is likely to be inhibited relative to, for example, the adsorption of charged superoxide radical anion $\left(\mathrm{O}_{2}{ }^{--}\right)$unless the free energy of adsorption of $\mathrm{O}_{2}$ molecule is very exothermic on a specific catalyst surface. This is especially true under fuel cell conditions, where the cathodic reaction typically occurs at potentials well positive of the potential of zero charge (pzc). Multistep, multielectron transfer processes like ORR that involves many adsorbed intermediates are undoubtedly classified as an inner-sphere electron transfer reaction. However, among the many elementary reaction steps involved in ORR, there could be a surface-independent outer-sphere electron transfer component in the overall electrocatalytic $4 e^{-}$inner-sphere electron transfer reaction. In that perspective, $\mathrm{O}_{2}$ reduction by one-electron transfer to superoxide $\left(\mathrm{O}_{2}{ }^{--}\right)$is observed at $E^{\circ}=-0.3 \pm 0.03 \mathrm{~V}$ versus $\mathrm{SHE}$ corresponding to $\Delta G^{\circ}=30 \pm$ $2 \mathrm{~kJ} \mathrm{~mol}^{-1}$ with both $\mathrm{O}_{2}$ and $\mathrm{O}_{2}{ }^{\bullet-}$ remaining in the aqueous phase $[13,14]$. Given the $\mathrm{pH}$ independence of this redox couple $\left(\mathrm{O}_{2} / \mathrm{O}_{2}{ }^{-}\right)$, the potential of this reaction does not change as the $\mathrm{pH}$ is varied from zero to fourteen [15]. Due to the occurrence of four proton transfer steps in $\mathrm{O}_{2}$ reduction to $\mathrm{H}_{2} \mathrm{O} / \mathrm{OH}^{-}$, its standard reduction potential changes by $0.828 \mathrm{~V}$ from $1.229 \mathrm{~V}$ to $0.401 \mathrm{~V}$ versus SHE as the $\mathrm{pH}$ value changes from zero to fourteen. This causes the overpotential for the first electron transfer step $\left(\mathrm{O}_{2} / \mathrm{O}_{2}{ }^{--}\right)$to decrease from $1.53 \mathrm{~V}$ at $\mathrm{pH}=0$ to $0.7 \mathrm{~V}$ at $\mathrm{pH}=14$ indicating a sharp decrease in overpotential at alkaline $\mathrm{pH}$ conditions. Blizanac et al. [15] argued based on a modified Pourbaix diagram approach that the above-mentioned decrease in overpotential is the primary thermodynamic reason for the applicability of a wide range of nonnoble materials in alkaline media. Due to the high overpotential required for $\mathrm{O}_{2} / \mathrm{O}_{2}{ }^{--}$redox couple in acidic media, only certain specific catalyst surfaces such as platinum that offer high free energy of adsorption for $\mathrm{O}_{2}$ can catalyze ORR in acidic media. While the decrease in overpotential for the first electron transfer in alkaline media is certainly significant, this argument is primarily of thermodynamic origin. The concept of involving the possibilities of outer-sphere electron transfer during ORR in alkaline media bears importance, and it was pointed out earlier by Bockris [16] and Appleby [17] that the exchange current density values in alkaline media exhibit near independence on a large number of electrode materials including silver, gold, manganese oxides, perovskites, and various carbon surfaces. So certain steps in the overall ORR process in alkaline media could proceed via a non-electrocatalytic mechanism [17].

The drive to replace expensive and scarce Pt-based catalysts for ORR has led to a class of electrocatalysts composed of first-row transition-metal ions stabilized by surface nitrogen functionalities on graphitic surfaces [2, 18-21]. The nature of the active site (obtained after heat treatment) in terms of its location on the carbon support (edge versus basal plane) [22], coordination number $\left(\mathrm{Fe}-\mathrm{N}_{4}\right.$ versus non-Fe- $\mathrm{N}_{4}$ environment) [23], and chemical identity of the nitrogen functional groups (pyridinic, pyrrolic, and quaternary) [24] have remained a key aspect of intense discussion. Several theories exist to explain the nature of the active site such as those proposed by van Veen et al. [25-27], McBreen et al. [28], Schulenburg et al. [29], Yeager et al. [2, 30], Scherson et al. [31-33], and Dodelet et al. [22, 34-45]. Although some authors observed that ORR is conducted by sites comprised of surface nitrogen groups devoid of any metal ion centers $[46,47]$, it is now widely accepted that the transition-metal ion centers coordinated to four nitrogen groups $\left(\mathrm{Me}-\mathrm{N}_{4}\right)$ on graphitic surfaces constitute the active site [22, 23, 30, 48 ], whereas chelation primarily serves to prevent the metal center from passivation/corrosion under electrochemical conditions [49]. Besides the exact structure of the active site, the low active site density or the metal loading that is obtained in these catalysts eludes clear understanding. A maximum in catalytic activity is obtained at a very low metal loading $(\sim 5000 \mathrm{ppm}$ by weight for inorganic precursors and $\sim 2 \mathrm{wt} \%$ for macrocycle precursors) [35]. Dodelet et al. [50] suggested that only the microporosity generated during pyrolysis upon gasification of disordered carbon content acts as a host for active sites. Irrespective of whatever the exact nature of the active site is, this does not necessarily explain the fundamental origin of ORR activity in this class of heattreated catalysts. It was recently pointed out by Bezerra et al. [51] and Garsuch et al. [52] that most studies on this class of materials have focused on the optimal synthesis conditions and structure necessary for maximum activity, whereas a more fundamental understanding will be of great help in developing innovative routes for new catalyst synthesis.

In this paper, we present a systematic study of ORR reaction mechanisms on $\mathrm{Pt}$ and non-Pt surfaces. Fundamental reasons for the so-called kinetic facility of ORR in alkaline media are investigated from the perspectives of the changes in the double-layer structure and the reaction mechanisms in transitioning from acidic to alkaline conditions. New evidence unraveling the influences of inner-sphere and outer-sphere electron transfer mechanisms during ORR is elucidated. Besides the efforts to understand the nature of the active site in heat-treated metal macrocycle-based catalysts, a combination of electrochemical and advanced $\mathrm{X}$-ray absorption spectroscopy techniques has been utilized to understand (1) the fundamental origin of electrocatalytic ORR activity upon heat treatment and (2) the reasons for the low density of active metal sites. To this end, a comparative study of ORR on $\mathrm{Pt}$ and non-Pt surfaces in both acid and alkaline media has been performed to (1) analyze the influence of both inner-sphere and outersphere electron transfer mechanisms, (2) elucidate the ORR reaction mechanisms, and (3) understand the importance of stabilization of the reaction intermediates on the active site.

\section{Experimental}

2.1. Electrochemical Characterization. All electrochemical measurements were made at room temperature using a rotating ring-disk electrode (RRDE) setup from Pine Instruments connected to an Autolab (Ecochemie Inc., model-PGSTAT 30) bipotentiostat. Alkaline $(0.1 \mathrm{M} \mathrm{NaOH})$ and acidic $\left(0.1 \mathrm{M} \mathrm{HClO}_{4}\right)$ electrolytes were prepared using sodium 
hydroxide pellets (semiconductor grade, 99.99\%, SigmaAldrich) and double-distilled 70\% perchloric acid (GFS Chemicals), respectively. $30 \% \mathrm{Pt} / \mathrm{C}$ catalyst from BASFETEK (Somerset, NJ) was used as received. Ru/C catalyst was synthesized in-house via aqueous route at a metal loading of $20 \%$ by weight [53]. Iron(III) meso-tetraphenylporphyrin chloride (FeTPPCl) was procured from Alfa Aesar. FeTPPCl was mixed with Black Pearl carbon in the mass ratio $1: 4$ and ball milled for 2 hours at $400 \mathrm{rpm}$ followed by pyrolysis at $800^{\circ} \mathrm{C}$ for 2 hours under argon atmosphere. Catalyst inks were prepared by dispersing $25 \mathrm{mg}$ of the catalyst in $10 \mathrm{~mL}$ of $1: 1$ millipore $\mathrm{H}_{2} \mathrm{O}$ : isopropyl alcohol mixture along with $100 \mu \mathrm{L}$ of $5 \mathrm{wt} \%$ Nafion $^{(\mathrm{R})}$ solution as a binder. $10 \mu \mathrm{L}$ aliquot of the catalyst ink was dispensed on Glassy Carbon (GC) disk of $5.61 \mathrm{~mm}$ dia. Gold ring electrode was held at $1.1 \mathrm{~V}$ versus RHE in alkaline electrolyte and at $1.3 \mathrm{~V}$ versus RHE in acidic electrolyte to detect stable peroxide intermediate. Collection efficiency of the disk-ring electrode was 37.5\%. All potentials are referred to reversible hydrogen electrode (RHE) scale prepared from the same solution as the bulk electrolyte unless otherwise stated.

2.2. X-Ray Absorption Spectroscopic (XAS) Measurements. The in situ XAS studies at Fe K-edge $(7112 \mathrm{eV})$ were performed at X19A beamline of National Synchrotron Light Source (NSLS, Brookhaven National Laboratory, NY). Detailed information on the spectroelectrochemical cell design are given elsewhere [54]. Spectra at Fe K-edge were collected in fluorescence mode using a PIPS detector. Argonor oxygen-saturated $0.1 \mathrm{M} \mathrm{NaOH}$ was used as the electrolyte. Complete details on data analysis of X-ray absorption near edge structure (XANES) and extended X-ray absorption fine structure (EXAFS) are available elsewhere [54]. Typical $\mathrm{k}$-range window during EXAFS fit was $2.500-12.500 \AA^{-1}$ (Kaiser-Bessel). Data analysis for Delta-mu $(\Delta \mu)$ studies at $\mathrm{Fe} \mathrm{K}$-edge involved specific normalization procedures detailed elsewhere $[54,55]$. Briefly, this involves careful calibration of edge energy (Fe K-edge $7112 \mathrm{eV}$ ), alignment to standard reference scan to account for any drift in the beam energy. A postedge normalization procedure was then applied to the aligned scans via a cubic spline function which normalizes the oscillations over a specific energy range (typically 25 to $200 \mathrm{eV}$ with respect to $E_{0}$ ) on a per-atom basis. Difference spectra were obtained using the equation $\Delta \mu=\mu(\mathrm{V})-\mu(0.1 \mathrm{~V})$, where $\mu(\mathrm{V})$ is the XANES spectra of the catalyst at various potentials and $\mu(0.1 \mathrm{~V})$ is the reference XANES signal at $0.1 \mathrm{~V}$ at which potential no evidence for electrochemical adsorbates $\left(\mathrm{H}_{\text {upd }}, \mathrm{O}_{\mathrm{ads}}, \mathrm{OH}_{\mathrm{ads}}\right)$ were found on iron-based catalysts. Theoretical delta-mu curves $\left(\Delta \mu_{t}\right)$ were constructed using the FEFF 8.0 code [56]. This was accomplished using the relationship $\Delta \mu_{t}=\mu\left(\mathrm{O}_{\mathrm{ads}}-\mathrm{Fe}-\mathrm{N}_{x^{-}}\right.$ C) $-\mu\left(\mathrm{Fe}-\mathrm{N}_{x}-\mathrm{C}\right)$, where the oxide species $\left(\mathrm{O}_{\mathrm{ads}}\right.$ or $\left.\mathrm{OH}_{\mathrm{ads}}\right)$ is in a specific binding site on $\mathrm{Fe}$.

\section{Results and Discussions}

3.1. ORR on Carbon-Supported Platinum Nanoparticles: Acid versus Alkaline Media. Figure 1 provides a snapshot of the cyclic voltammetry (CV) and ORR on $30 \% \mathrm{Pt} / \mathrm{C}$ in $0.1 \mathrm{M}$
$\mathrm{NaOH}$ and $0.1 \mathrm{M} \mathrm{HClO}_{4}$ electrolytes. As shown in Figure 1 (a), CV of $30 \% \mathrm{Pt} / \mathrm{C}$ catalyst features the typical hydrogen underpotential deposition/stripping region below $0.5 \mathrm{~V}$ versus RHE in both of the electrolytes followed by oxide formation on $\mathrm{Pt}$ at potentials above $0.7 \mathrm{~V}$ versus RHE. Oxide formation on $\mathrm{Pt}$ in acidic media is due to oxidation of the solvent water molecules (water activation) [57] and in alkaline media is due to specific adsorption of hydroxide anions from the supporting electrolyte $[58,59]$. The onset potential of Pt-OH formation is similar in both electrolytes, although in alkaline media oxide formation current exhibits a characteristic peak shape whereas in acidic media oxide formation current is relatively more flat. Half-wave potential $\left(E_{1 / 2}\right)$ of $\mathrm{Pt}-\mathrm{OH}$ in $0.1 \mathrm{M} \mathrm{NaOH}$ is $0.775 \mathrm{~V}$ whereas in $0.1 \mathrm{M} \mathrm{HClO}_{4} E_{1 / 2}$ of Pt-OH formation is shifted slightly more positive to $0.810 \mathrm{~V}$. Figure $1(\mathrm{~b})$ shows the ring current measured during ORR on $\mathrm{Pt} / \mathrm{C}$ at $900 \mathrm{rpm}$ in $0.1 \mathrm{M} \mathrm{HClO}_{4}$ and $0.1 \mathrm{M} \mathrm{NaOH}$. The corresponding ORR polarization curves are shown in the inset of Figure 1(b). The ORR onset potential in both of the electrolytes is $\sim 1 \mathrm{~V}$ versus RHE which is followed by mixed kinetic-diffusion region between the potentials $0.7 \mathrm{~V}$ and $1 \mathrm{~V}$. Well-defined diffusionlimited current density region is observed below $0.6 \mathrm{~V}$ versus RHE. The marginally higher Pt-OH coverage in alkaline media (between the potential region of $0.9 \mathrm{~V}$ to $0.8 \mathrm{~V}$ versus RHE) causes a penalty of $\sim 25 \mathrm{mV}$ higher overpotential at a kinetic current density of $i_{k}=1 \mathrm{~mA} \mathrm{~cm}^{-2}$ geo for ORR in $0.1 \mathrm{M} \mathrm{NaOH}$ relative to $0.1 \mathrm{M} \mathrm{HClO}_{4}$. The most interesting observation in this experiment using $\mathrm{Pt} / \mathrm{C}$ is in the ring currents measured during ORR. As seen in Figure 1(b), in $0.1 \mathrm{M} \mathrm{HClO}_{4}$ the ring current due to peroxide oxidation is lower in the entire potential region and does not show any significant increase until the disk potential enters the $\mathrm{H}$ UPD region. On the contrary, the ring current due to peroxide oxidation in $0.1 \mathrm{M} \mathrm{NaOH}$ electrolyte shows a sharp increase at $0.9 \mathrm{~V}$ in the cathodic scan. The sharp increase in ring current at $0.9 \mathrm{~V}$ during ORR in alkaline media is closely related to $\mathrm{Pt}-\mathrm{OH}$ formation from specific adsorption of hydroxide anions as seen from the $\mathrm{CV}$ in $0.1 \mathrm{M} \mathrm{NaOH}$. As shown in Figure $1(\mathrm{a})$, in $0.1 \mathrm{M} \mathrm{NaOH}$ electrolyte, Pt-OH formation commences at $\sim 0.7 \mathrm{~V}$ versus RHE and reaches a peak current at $0.81 \mathrm{~V}$ and a plateau at $\sim 0.9 \mathrm{~V}$. On the cathodic direction, the peak potential for $\mathrm{Pt}-\mathrm{OH}$ reduction is $\sim 0.75 \mathrm{~V}$ versus RHE. As seen in Figure $1(\mathrm{~b})$, on the cathodic ORR scan, the increase in ring current commences at $0.9 \mathrm{~V}$ and reaches a peak potential of $0.75 \mathrm{~V}$ versus RHE. This clearly establishes the interaction between molecular oxygen and the hydroxyl species on the surface. This peroxide formation in the mixed kinetic-diffusion region in alkaline media is more evident at a higher electrolyte concentration of $1.0 \mathrm{M} \mathrm{NaOH}$ as shown in Figure 1(c). At a higher concentration of alkaline electrolyte, that is, at $1 \mathrm{M} \mathrm{NaOH}$, peroxide is detected at the ring electrode in both the anodic and the cathodic scan [60].

In order to explain the link between the specifically adsorbed hydroxide anions and the peroxide detected in the mixed kinetic-diffusion region in alkaline media, it is important to understand the double-layer structure of the electrode-electrolyte interface during ORR at high-pH 


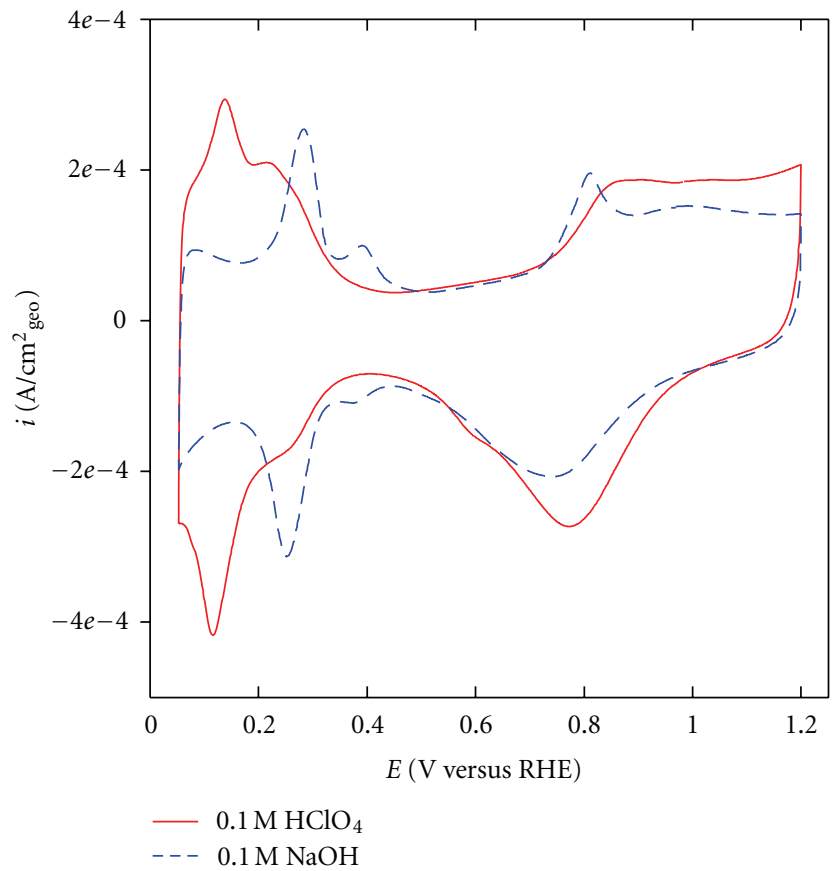

(a) Cyclic voltammetry

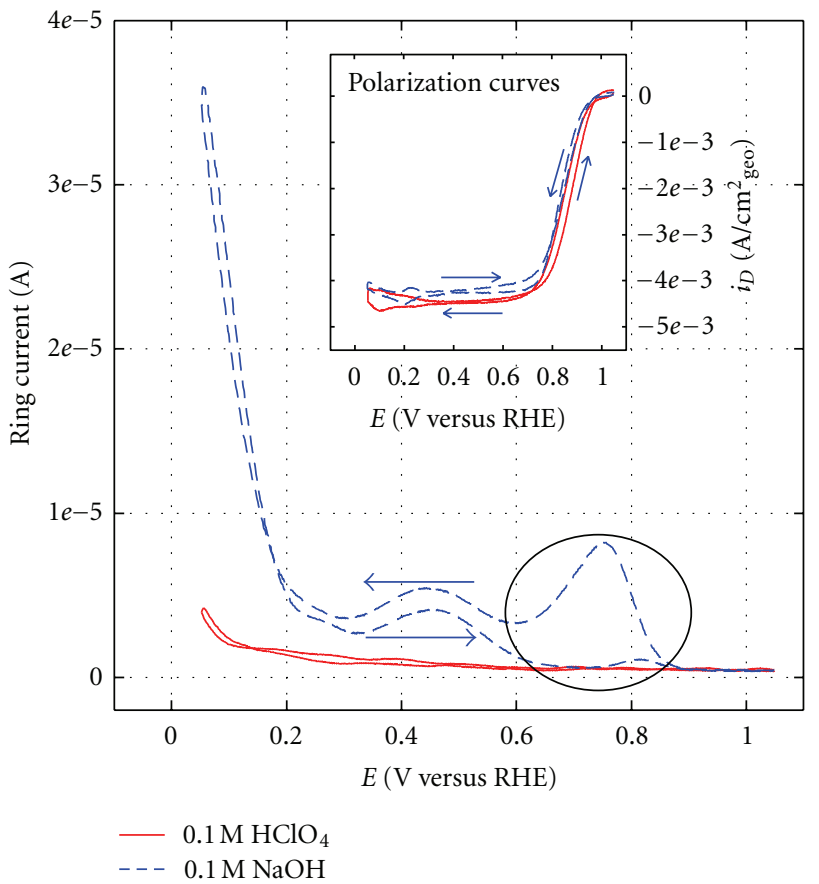

(b)

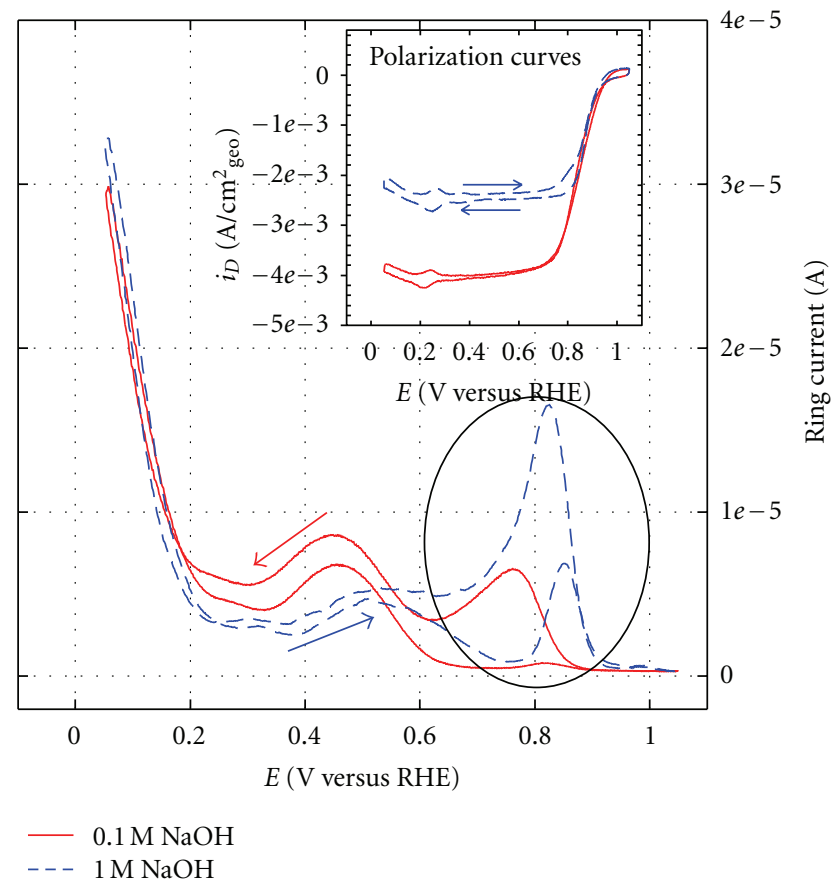

(c)

Figure 1: Comparison of electrochemical characteristics of BASF-ETEK 30\% $\mathrm{Pt} / \mathrm{C}$ in $0.1 \mathrm{M} \mathrm{HClO}_{4}, 0.1 \mathrm{M} \mathrm{NaOH}$, and $1.0 \mathrm{M} \mathrm{NaOH}$

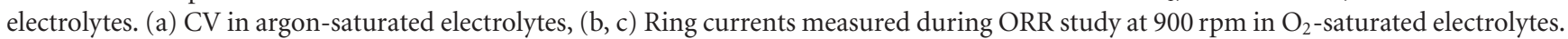
Insets in (b, c) show the corresponding ORR polarization curves at $900 \mathrm{rpm}$. Scan rate: $20 \mathrm{mV} / \mathrm{s} . E_{\text {Ring }}=1.1 \mathrm{~V}$ versus RHE in $0.1 \mathrm{M} \mathrm{NaOH}$ and $1.3 \mathrm{~V}$ versus RHE in $0.1 \mathrm{M} \mathrm{HClO}_{4}$. Catalyst loading: $15 \mu \mathrm{g}_{\mathrm{Pt}} / \mathrm{cm}^{2}$ on $5.61 \mathrm{~mm}$ Glassy Carbon disk electrode.

environments. A schematic illustration of the double-layer structure is shown in Figure 2. In an operating fuel cell, cathodic ORR process typically occurs at potentials well positive of the potential of zero charge (pzc). In alkaline media, water molecules not only act as solvent but also serve as the source of protons required in ORR. At these conditions in alkaline media, inner Helmholtz plane (IHP) is populated by specifically adsorbed hydroxyl species, solvent water dipoles (oriented with the oxygen atom towards the electrode surface), and chemisorbed $\mathrm{O}_{2}$. Alkali metal ions 


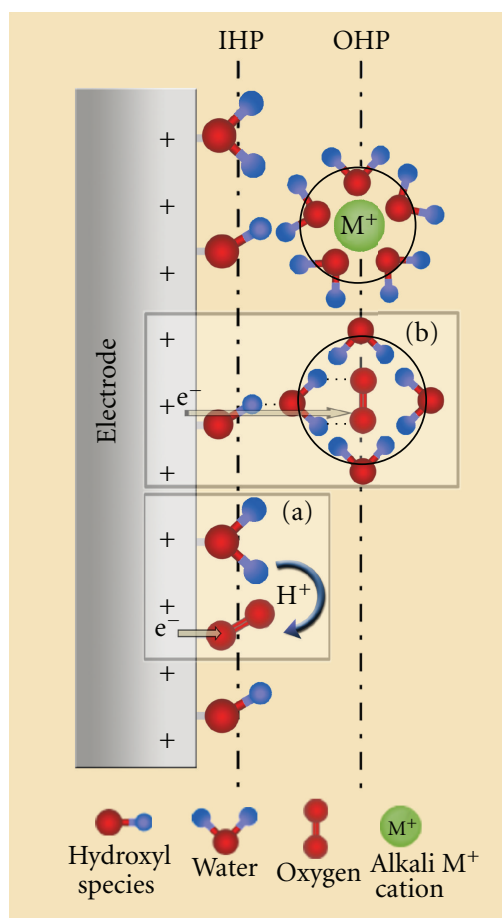

Figure 2: Schematic illustration of the double-layer structure during ORR in alkaline media. Insets $(\mathrm{a}, \mathrm{b})$ illustrate the inner- and outer-sphere electron transfer processes.

are typically well solvated and are classically expected to populate the outer Helmholtz plane (OHP). In ORR, the case of a typical electrocatalytic inner-sphere electron transfer mechanism involves strong chemisorption of molecular $\mathrm{O}_{2}$ (with or without bond breaking) on oxide-free $\mathrm{Pt}$ active sites followed by $4 \mathrm{e}^{-} / 4 \mathrm{H}^{+}$transfer. This inner-sphere mechanism depicted in Figure 2 (inset (a)) is common to both acidic and alkaline media, wherein all the reaction intermediates remain adsorbed on the active site until the final product is desorbed into the bulk electrolyte. Also shown in Figure 2 (inset (b)) is the outer-sphere electron transfer mechanism that appears to be unique to the alkaline conditions. The solvated molecular $\mathrm{O}_{2}$, represented here as a cluster $\mathrm{O}_{2} \cdot\left(\mathrm{H}_{2} \mathrm{O}\right)_{n}$, could interact with the surface hydroxyl species $\left(\mathrm{OH}_{\mathrm{ads}}\right)$ via a hydrogen bond between $\mathrm{H}$ atom in $\mathrm{OH}_{\mathrm{ads}}$ and $\mathrm{O}$ atom in the solvent water molecule. Such hydrogen bond energies $\left(<35 \mathrm{~kJ} \mathrm{~mol}^{-1}\right)$ are typically much lower than the energy associated with covalent bond strength such as in the case of direct chemisorption of $\mathrm{O}_{2}$ on $\mathrm{Pt}\left(>300 \mathrm{~kJ} \mathrm{~mol}^{-1}\right)$ [61]. This hydrogen bond formation stabilizes the solvated molecular oxygen $\mathrm{O}_{2} \cdot\left(\mathrm{H}_{2} \mathrm{O}\right)$ cluster in the OHP and promotes an outer-sphere electron transfer to form the superoxide species.

Following this new evidence on the involvement of outer-sphere electron transfer in alkaline media, two ORR mechanisms at high-pH environment are proposed here. The first is the well-known electrocatalytic inner-sphere electron transfer mechanism, where molecular $\mathrm{O}_{2}$ undergoes direct chemisorption on oxide-free Pt site leading to a direct/series $4 \mathrm{e}^{-}$pathway without the desorption of reaction

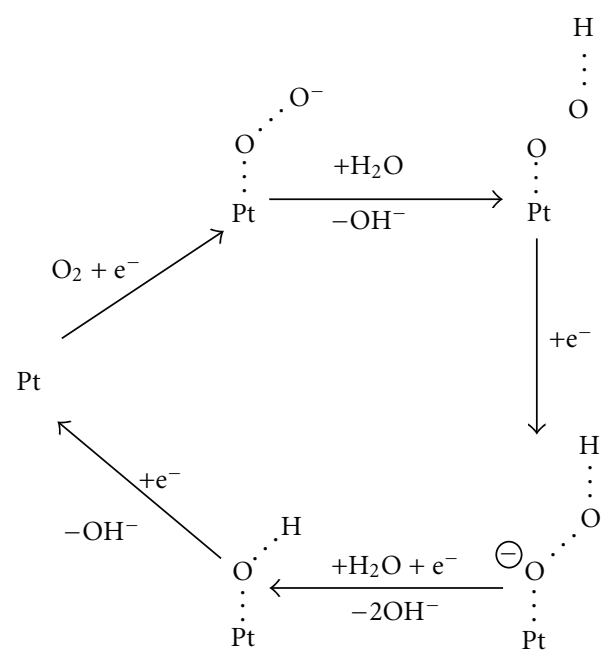

FIGURE 3: Electrocatalytic inner-sphere electron transfer mechanism for ORR on $\mathrm{Pt}$ in alkaline media assuming end-on adsorption of $\mathrm{O}_{2}$ on a single Pt active site.

intermediates (such as peroxide) from the surface according to the following well-known reaction scheme (also depicted in Figure 3) [3]:

$$
\begin{gathered}
\mathrm{O}_{2} \longrightarrow \mathrm{O}_{2, \mathrm{ads}}, \\
\mathrm{O}_{2, \mathrm{ads}}+\mathrm{H}_{2} \mathrm{O}+2 \mathrm{e}^{-} \longrightarrow\left(\mathrm{HO}_{2}^{-}\right)_{\mathrm{ads}}+\mathrm{OH}^{-}, \\
\left(\mathrm{HO}_{2}^{-}\right)_{\mathrm{ads}}+\mathrm{H}_{2} \mathrm{O}+2 \mathrm{e}^{-} \longrightarrow 3 \mathrm{OH}^{-} .
\end{gathered}
$$

The second is the outer-sphere electron transfer mechanism, where solvated molecular $\mathrm{O}_{2}$ cluster $\mathrm{O}_{2} \cdot\left(\mathrm{H}_{2} \mathrm{O}\right)_{n}$ weakly interacts with adsorbed hydroxyl species to promote a $2 \mathrm{e}^{-}$ reaction pathway to $\mathrm{HO}_{2}{ }^{-}$anion as a reaction product which desorbs from the surface and is eventually detected at the ring electrode. This reaction is formulated as follows:

$$
\begin{aligned}
& \mathrm{M}-\mathrm{OH}+\left[\mathrm{O}_{2} \cdot\left(\mathrm{H}_{2} \mathrm{O}\right)_{n}\right]_{\mathrm{aq}}+\mathrm{e}^{-} \\
& \quad \longrightarrow \mathrm{M}-\mathrm{OH}+\left(\mathrm{HO}_{2}\right)_{\mathrm{ads}}+\mathrm{OH}^{-}+\left(\mathrm{H}_{2} \mathrm{O}\right)_{n-1}, \\
& \left(\mathrm{HO}_{2}{ }^{\bullet}\right)_{\mathrm{ads}}+\mathrm{e}^{-} \longrightarrow\left(\mathrm{HO}_{2}^{-}\right)_{\mathrm{ads}} \\
& \left(\mathrm{HO}_{2}^{-}\right)_{\mathrm{ads}} \longrightarrow\left(\mathrm{HO}_{2}^{-}\right)_{\mathrm{aq}} \cdot
\end{aligned}
$$

The first step in the previous reaction shown in (3) involves electron transfer (or tunneling) from the electrode surface across a thin oxide film and at least one layer of solvation shell to solvated $\mathrm{O}_{2}$. Equation (3) involves several elementary steps as written in the following:

$$
\begin{gathered}
\mathrm{M}-\mathrm{OH}+\left[\mathrm{O}_{2} \cdot\left(\mathrm{H}_{2} \mathrm{O}\right)_{n}\right]_{\mathrm{aq}}+\mathrm{e}^{-} \\
\longrightarrow \mathrm{M}-\mathrm{OH}+\left[\mathrm{O}_{2} \cdot-\cdot\left(\mathrm{H}_{2} \mathrm{O}\right)_{n}\right]_{\mathrm{aq}}, \\
{\left[\mathrm{O}_{2}{ }^{\bullet-} \cdot\left(\mathrm{H}_{2} \mathrm{O}\right)_{n}\right]_{\mathrm{aq}} \longrightarrow\left(\mathrm{O}_{2}{ }^{--}\right)_{\mathrm{ads}}+n \mathrm{H}_{2} \mathrm{O},} \\
\left(\mathrm{O}_{2}{ }^{--}\right)_{\mathrm{ads}}+\mathrm{H}_{2} \mathrm{O} \longrightarrow\left(\mathrm{HO}_{2}\right)_{\mathrm{ads}}+\mathrm{OH}^{-} .
\end{gathered}
$$


First electron transfer to $\mathrm{O}_{2, \mathrm{aq}}$ forms $\left(\mathrm{O}_{2}{ }^{--}\right)_{\mathrm{aq}}$ which then undergoes desolvation and subsequent adsorption on the oxide substructure of the $\mathrm{Pt}$ surface to form $\left(\mathrm{O}_{2}{ }^{--}\right)_{\mathrm{ads}}$, followed by proton transfer to form adsorbed hydroperoxyl radical, $\left(\mathrm{HO}_{2}{ }^{\bullet}\right)_{\text {ads }}$. Second electron transfer to $\left(\mathrm{HO}_{2}{ }^{\bullet}\right)_{\text {ads }}$ yields $\left(\mathrm{HO}_{2}{ }^{--}\right)_{\mathrm{ads}}$. The binding energy of $\left(\mathrm{HO}_{2}{ }^{\cdot-}\right)_{\mathrm{ads}}$ on the oxide substructure of Pt is likely to be lower than that on oxide-free Pt site. This leads to the facile desorption of $\mathrm{HO}_{2}{ }^{-}$ anion into the electrolyte which is eventually detected at the ring electrode. Also hydrogen peroxide anion formed via the homogeneous chemical disproportionation of superoxide anion would also be detected at the ring electrode. The interaction between the $\mathrm{O}_{2} \cdot\left(\mathrm{H}_{2} \mathrm{O}\right)_{n}$ cluster and the surface hydroxyl species causes certain nonspecificity to the identity of the underlying electrode metal. This nonspecificity opens the gate to use a wide-range of nonnoble metals and their oxides as electrode materials for ORR in alkaline media. On noble metals such as $\mathrm{Pt}$, this nonspecificity is observed only in the oxide formation region, and depending on the extent of $-\mathrm{OH}$ coverage both inner- and outer-sphere electron transfer mechanisms coexist in alkaline media. On nonnoble metals such as the first-row transition elements that are completely passivated by a layer oxide film upon immersion into the aqueous electrolyte, this outer-sphere electron transfer process is likely to be the dominant mechanism. Furthermore as identified in Figures 1(b) and 1(c), we consider the peakshaped ring current in the potential range of $0.6 \mathrm{~V}$ to $0.9 \mathrm{~V}$ in alkaline media to be a characteristic signature of the outer-sphere electron transfer reaction mechanism. In acidic media, the adsorbed $\mathrm{OH}_{\text {ads }}$ species from water activation primarily serve only to block/inhibit the adsorption of molecular $\mathrm{O}_{2}$ and other reaction intermediates via the wellknown site-blocking effect $[62,63]$. However, as shown here in alkaline media, the $\mathrm{OH}_{\text {ads }}$ species not only block the direct adsorption of $\mathrm{O}_{2}$ but also serve to promote the $2 \mathrm{e}^{-}$ outer-sphere electron transfer reaction to peroxide. There are several precedents for electrochemical reactions which are mediated and/or promoted by specifically adsorbed anions and surface functional groups [64-67]. The anions or the surface groups act as an outer-sphere bridge between the reactant and the electrode surface. Furthermore as seen in Figures $1(\mathrm{~b})$ and $1(\mathrm{c})$, peroxide intermediate is detected at the ring electrode at $0.5 \mathrm{~V}$ and also below $0.3 \mathrm{~V}$ versus RHE, and the reason for this was explained in detail in an earlier publication $[53,60]$. Briefly, in alkaline media, the peak in ring current at $0.50 \mathrm{~V}$ is due to the carbon support and the increase in ring current below $0.3 \mathrm{~V}$ is due to reorientation of the water molecules at the electrode surface $[53,60]$.

In light of this new evidence of involvement of outersphere electron transfer mechanism during ORR in alkaline media, it is noted that, while this mechanism allows the possibility of nonnoble metals to be used as electrode materials, it predominantly seems to yield the $2 \mathrm{e}^{-}$peroxide intermediate as the final product. So, for efficient $4 \mathrm{e}^{-}$conversion of $\mathrm{O}_{2}$, it is important to facilitate direct adsorption of desolvated molecular $\mathrm{O}_{2}$ on the $\mathrm{OH}$-free active site and avoid the precipitous reaction of solvated molecular $\mathrm{O}_{2}$ with the $\mathrm{OH}$-covered active site. In agreement with Bard [12], this implies the necessity to promote the electrocatalytic inner-sphere electron transfer mechanism for efficient $4 \mathrm{e}^{-}$ reduction of oxygen.

3.2. ORR on Heat-Treated Carbon-Supported Ru Nanoparticles. Figure 4 shows the ORR on $\mathrm{Ru} / \mathrm{C}$ catalyst in $\mathrm{O}_{2}$ saturated $0.1 \mathrm{M} \mathrm{NaOH}$ and $0.1 \mathrm{M} \quad \mathrm{HClO}_{4}$ electrolytes recorded at $900 \mathrm{rpm}$. The ORR onset potential for $\mathrm{Ru} / \mathrm{C}$ in $0.1 \mathrm{M} \mathrm{HClO}_{4}$ is $0.78 \mathrm{~V}$ versus RHE, whereas in $0.1 \mathrm{M} \mathrm{NaOH}$ it is $0.9 \mathrm{~V}$ versus RHE. In the alkaline media, mixed kineticdiffusion region between $0.9 \mathrm{~V}$ and $0.5 \mathrm{~V}$ is ensued by a welldefined limiting current region below $0.5 \mathrm{~V}$ versus RHE. In the acidic electrolyte, ORR is kinetically controlled as indicated by the absence of any clear diffusion-limited current region even at very high overpotentials. As shown in Figure 4 (b) at a kinetic current density of $0.1 \mathrm{~mA} \mathrm{~cm}^{-2}$ geo, $\mathrm{Ru} / \mathrm{C}$ exhibits $\sim 125 \mathrm{mV}$ lower overpotential in $0.1 \mathrm{M} \mathrm{NaOH}$ than in $0.1 \mathrm{M} \mathrm{HClO}_{4}$. Primary reasons to this lower overpotential in alkaline media are delineated here. As seen in Figure 4(c) between the potential regions of $0.7 \mathrm{~V}$ to $0.8 \mathrm{~V}$, the shoulder in ring current in $0.1 \mathrm{M} \mathrm{NaOH}$ electrolyte is characteristic of the outer-sphere electron transfer mechanism on oxidecovered $\mathrm{Ru} / \mathrm{C}$ catalyst in alkaline media. This outer-sphere reaction mechanism was depicted in (3)-(5) giving rise to the peroxide intermediate $\left(\mathrm{HO}_{2}^{-}\right)$as the final product at oxide-covered $\mathrm{Ru}$ sites. This $\left(\mathrm{HO}_{2}{ }^{-}\right)_{\mathrm{aq}}$ formed is detected at the ring electrode and appears as a shoulder in ring current between $0.7 \mathrm{~V}$ and $0.8 \mathrm{~V}$ as shown in Figure 4(c). In acidic media, peroxide detected is very minimal and about an order of magnitude lower than that in $0.1 \mathrm{M} \mathrm{NaOH}$. It should be noted that, in $0.1 \mathrm{M} \mathrm{NaOH}$, this outer-sphere electron transfer occurs only at oxide-covered $\mathrm{Ru}$ sites, whereas at oxide-free $\mathrm{Ru}$ sites direct molecular $\mathrm{O}_{2}$ adsorption should take place leading to efficient $4 \mathrm{e}^{-}$reduction of $\mathrm{O}_{2}$ to $\mathrm{OH}^{-}$ via an inner-sphere electrocatalytic pathway. So, in alkaline media, a combination of both inner-sphere and outer-sphere electron transfer mechanisms is operative. The consequence of this outer-sphere electron transfer in alkaline media is that this mechanism leads to higher concentration of $\mathrm{HO}_{2}{ }^{-}$to be generated near the electrode surface, that is, the double layer; however, no evidence for such an outer-sphere reaction is observed in acidic media. Higher activity of $\mathrm{HO}_{2}{ }^{-}$effectively shifts the potential of the electrode from that of the $\mathrm{O}_{2} / \mathrm{HO}_{2}{ }^{-}$ couple to that of the $\mathrm{HO}_{2}{ }^{-} / \mathrm{OH}^{-}$redox couple by carrying out $\mathrm{HO}_{2}{ }^{-}$reduction to $\mathrm{OH}^{-}$on oxide-free $\mathrm{Ru}$ sites. This is shown in Figure 4(d), where ORR and hydrogen peroxide reduction reaction (HPRR) are shown on $\mathrm{Ru} / \mathrm{C}$ catalyst in both $0.1 \mathrm{M} \mathrm{NaOH}$ and $0.1 \mathrm{M} \mathrm{HClO}_{4} \cdot 2 \mathrm{e}^{-}$reduction of hydrogen peroxide in acidic $\left(\mathrm{H}_{2} \mathrm{O}_{2} / \mathrm{H}_{2} \mathrm{O}\right)$ and alkaline media $\left(\mathrm{HO}_{2}{ }^{-} / \mathrm{OH}^{-}\right)$are written as follows [13]:

$$
\begin{aligned}
& \text { Acidic Media: } \mathrm{H}_{2} \mathrm{O}_{2}+2 \mathrm{H}^{+}+2 \mathrm{e}^{-} \longrightarrow 2 \mathrm{H}_{2} \mathrm{O} \\
& E^{\circ}=1.763 \mathrm{~V} \text { versus SHE}, \\
& \text { Alkaline Media: } \mathrm{HO}_{2}{ }^{-}+\mathrm{H}_{2} \mathrm{O}+2 \mathrm{e}^{-} \longrightarrow 3 \mathrm{OH}^{-} \\
& E^{\circ}=0.867 \mathrm{~V} \text { versus SHE. }
\end{aligned}
$$

As is well known, the standard reduction potentials of the above reactions are well positive of the $4 \mathrm{e}^{-}$reduction of 


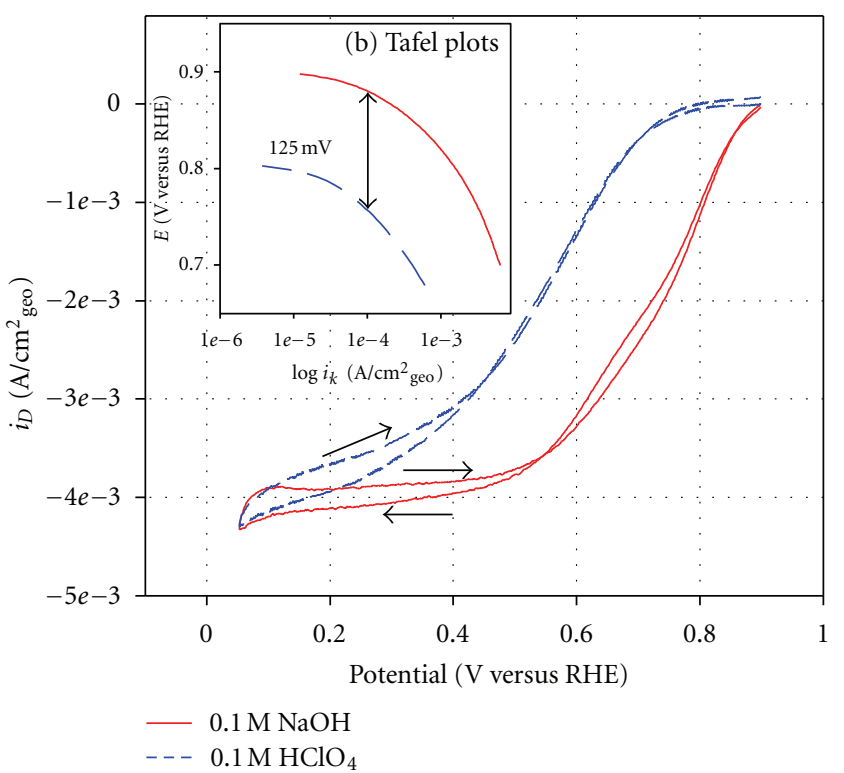

(a) Polarization curves

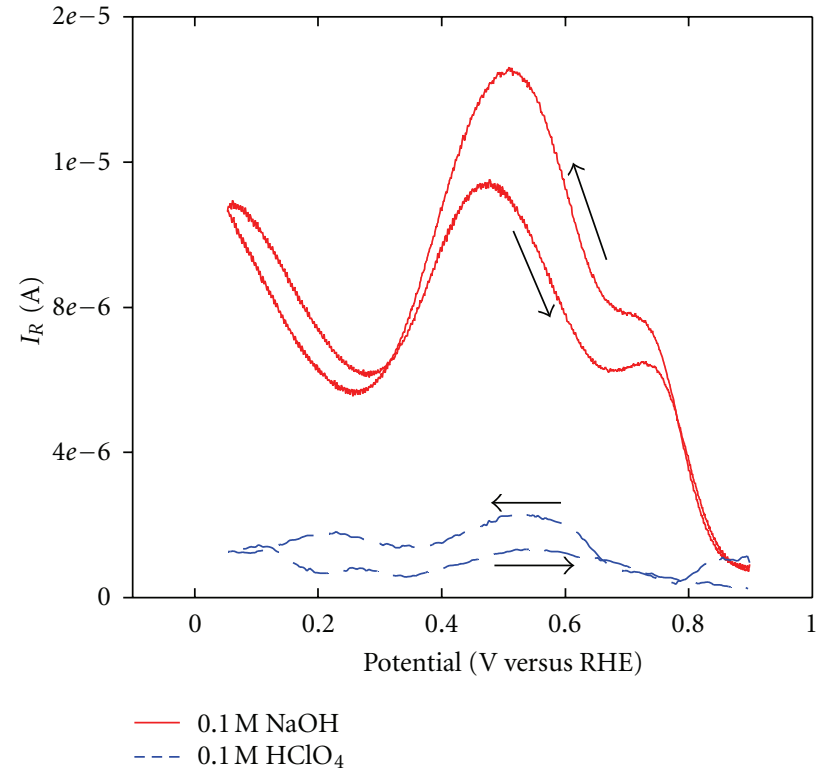

(c) Ring currents

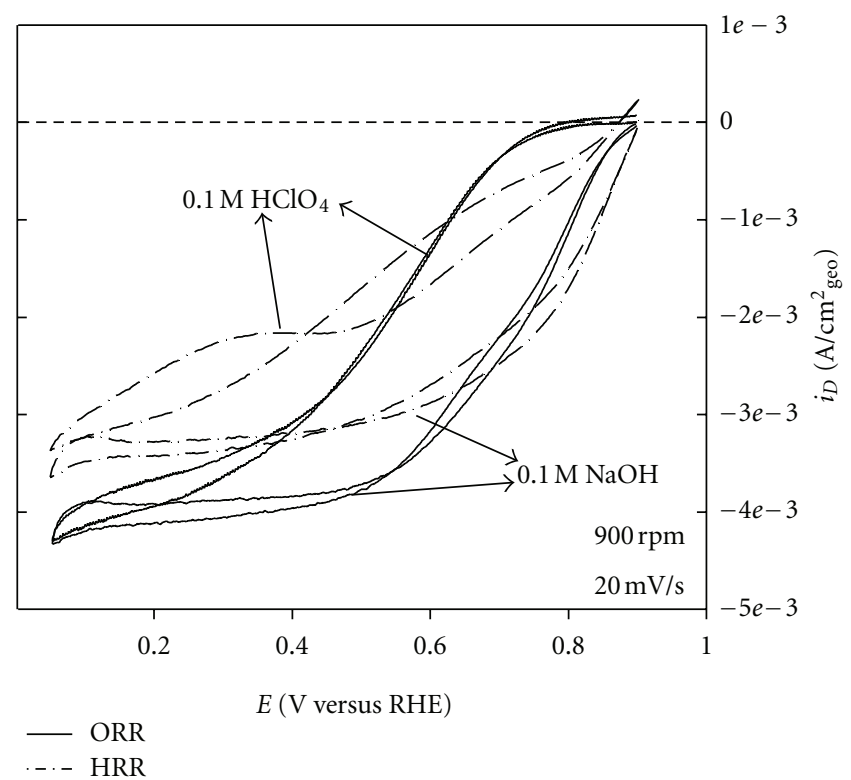

(d) $\mathrm{H}_{2} \mathrm{O}_{2}$ reduction

FIGURE 4: Oxygen reduction reaction on $\mathrm{Ru} / \mathrm{C}$ heat-treated (HT) catalyst in $0.1 \mathrm{M} \mathrm{NaOH}$ and $0.1 \mathrm{M} \mathrm{HClO}_{4}$ electrolytes. (a) ORR polarization curves at $900 \mathrm{rpm}$ and $20 \mathrm{mV} / \mathrm{s}$, (b) mass-transport-corrected Tafel plots, (c) ring current measured during ORR at $900 \mathrm{rpm}$. $E_{\text {Ring }}=1.1 \mathrm{~V}$ versus $\mathrm{RHE}$ in $0.1 \mathrm{M} \mathrm{NaOH}$ and $E_{\mathrm{Ring}}=1.3 \mathrm{~V}$ versus $\mathrm{RHE}$ in $0.1 \mathrm{M} \mathrm{HClO}_{4}$, and (d) hydrogen peroxide reduction reaction (HPRR) in comparison to ORR in $0.1 \mathrm{M} \mathrm{HClO}_{4}$ and $0.1 \mathrm{M} \mathrm{NaOH}$. HPRR is shown in oxygen-free electrolytes containing externally added $\mathrm{H}_{2} \mathrm{O}_{2}$ at a concentration of $3.5 \mathrm{mM}$.

molecular $\mathrm{O}_{2}$ in both acidic and alkaline electrolytes. So, from a thermodynamic perspective, any peroxide intermediate formed should be immediately reduced further. This is also kinetically true on ruthenium as shown in Figure $4(\mathrm{~d})$. Half-wave potential $\left(E_{1 / 2}\right)$ of HPRR on $\mathrm{Ru} / \mathrm{C}$ in $0.1 \mathrm{M}$ $\mathrm{NaOH}$ is $40 \mathrm{mV}$ positive compared to that of the $E_{1 / 2}$ of ORR [68]. So the kinetics of the reaction in alkaline media favors the immediate reduction of any peroxide intermediate generated during ORR. This is also true in acidic media although the shape of the HPRR profile in acidic media on $\mathrm{Ru} / \mathrm{C}$ requires more explanation. The onset potential of HPRR on $\mathrm{Ru} / \mathrm{C}$ in $0.1 \mathrm{M} \mathrm{HClO}_{4}$ is as high as $0.88 \mathrm{~V}$ which is only $20 \mathrm{mV}$ lower than ORR and HPRR onset potentials in $0.1 \mathrm{M} \mathrm{NaOH}$ electrolyte. As is known previously [69], $\mathrm{H}_{2} \mathrm{O}_{2}$ undergoes decomposition to $\mathrm{O}_{2}$ and $\mathrm{H}_{2} \mathrm{O}$ in acidic electrolyte at $\mathrm{Ru} / \mathrm{C}$ surface. This decomposition reaction that generates $\mathrm{O}_{2}$ near the electrode surface skews the HPRR profile in acidic media to higher overpotentials characteristic 
of ORR in acidic media. However, the aspect of relevance to the discussion here is that the kinetics of the system favors further reduction of hydrogen peroxide intermediate in both acidic and alkaline media. Once the $\mathrm{H}_{2} \mathrm{O}_{2} / \mathrm{HO}_{2}{ }^{-}$stable intermediate is generated, this species undergoes adsorption at oxide-free $\mathrm{Ru}$ sites and further reduces to $\mathrm{H}_{2} \mathrm{O} / \mathrm{OH}^{-}$ according to (7)/(9). So, any in situ generation of hydrogen peroxide intermediate should shift the potential to more positive values, and indeed this is what is observed in alkaline media. The in situ parallel generation of $\mathrm{HO}_{2}{ }^{-}$anion intermediate via the outer-sphere electron transfer reaction scheme shown in (3)-(5) serves to shift the ORR potential to more positive values in alkaline media. On the contrary, this excess parallel generation of $\mathrm{H}_{2} \mathrm{O}_{2}$ via the outer-sphere reaction mechanism is not observed in acidic media and, hence, the higher overpotential for ORR in acidic media. In general, this can also be further extended to other catalyst systems that exhibit lower ORR overpotential in alkaline media compared to that in acidic electrolytes. The prospects of modifying the carbon-supported ruthenium nanoparticle catalyst by chalcogen groups (S/Se) in order to suppress oxide formation and promote the inner-sphere electrocatalytic process by facilitating direct $\mathrm{O}_{2}$ adsorption was discussed recently as a separate treatise [70].

\subsection{Pyrolyzed Metal Macrocycle for Promoting Inner-Sphere} Electron Transfer. Figure 5(a) shows a comparison in dilute acidic and alkaline electrolytes of the ORR activity of FeTPP/C catalyst pyrolyzed at $800^{\circ} \mathrm{C}$. As observed in Figure 5 (a), the onset potential for ORR in $0.1 \mathrm{M} \mathrm{NaOH}$ is $0.95 \mathrm{~V}$ versus $\mathrm{RHE}$, whereas in $0.1 \mathrm{M} \mathrm{HClO}_{4}$ electrolyte it is $0.80 \mathrm{~V}$ versus RHE. This $150 \mathrm{mV}$ lower overpotential in alkaline media is clearly reflected over the entire mixed kinetic-diffusion region. In $0.1 \mathrm{M} \mathrm{NaOH}$ electrolyte, the mixed kinetic-diffusion region is ensued by a well-defined diffusion-limited region. In $0.1 \mathrm{M} \mathrm{HClO}_{4}$, no clear diffusionlimited region could be discerned, which is indicative of kinetic control in acidic media even at high overpotentials. At a potential of $0.80 \mathrm{~V}$ versus RHE, the ORR kinetic current density of FeTPP/C (pyrolyzed at $800^{\circ} \mathrm{C}$ ) is clearly four orders of magnitude higher in $0.1 \mathrm{M} \mathrm{NaOH}$ electrolyte than that in $0.1 \mathrm{M} \mathrm{HClO}_{4}$. For a given catalyst, the four orders of magnitude difference in kinetic activity between acidic and alkaline media are intriguing. Figure 5(b) shows the HPRR activity of FeTPP/C catalyst (pyrolyzed at $800^{\circ} \mathrm{C}$ ) in both acidic and alkaline media in comparison to the corresponding ORR polarization curves. The onset potential for peroxide reduction in $0.1 \mathrm{M} \mathrm{HClO}_{4}$ is $0.84 \mathrm{~V}$ versus $\mathrm{RHE}$, whereas in $0.1 \mathrm{M} \mathrm{NaOH}$ it is $1.01 \mathrm{~V}$ versus RHE. Besides this onset potential difference, in $0.1 \mathrm{M} \mathrm{NaOH}$ electrolyte, the mixed kinetic-diffusion region for peroxide reduction is more anodic compared to that of ORR in the same electrolyte which is then followed by a reasonably discernable diffusionlimited current density region. This clearly indicates that peroxide reduction in alkaline media is kinetically favored such that any peroxide intermediate formed during ORR in $0.1 \mathrm{M} \mathrm{NaOH}$ will be immediately reduced to the $4 \mathrm{e}^{-}$product. On the contrary, the reduction of hydrogen peroxide in acidic media is kinetically unfavorable due to weak binding of $\mathrm{H}_{2} \mathrm{O}_{2}$ on the active site leading to its desorption into the bulk electrolyte and/or catalytic decomposition to molecular $\mathrm{O}_{2}$. This clearly demonstrates that stabilizing the peroxide intermediate on the active site is important in effectively carrying out $4 e^{-}$ORR process, and the higher stability of peroxide intermediate on the active site leads to the so-called kinetic facility in alkaline media but not in acidic media. Given the $\mathrm{p} K_{a}$ values for the first and second ionization of $\mathrm{H}_{2} \mathrm{O}_{2}$ at $25^{\circ} \mathrm{C}\left(\mathrm{p} K_{1}=11.69\right.$ and $\left.\mathrm{p} K_{2}=\sim 20\right)$, the predominant peroxide species for $\mathrm{pH}<12$ is $\mathrm{H}_{2} \mathrm{O}_{2}$ whereas at $\mathrm{pH}>12$ it is $\mathrm{HO}_{2}{ }^{-}$[58]. This leads to the formation of a stable Lewis acid-base adduct in alkaline media $\left(\mathrm{Fe}^{2+}-\mathrm{HO}_{2}{ }^{-}\right)$that enables complete $4 \mathrm{e}^{-}$transfer. On the contrary, the lack of stabilization of $\left(\mathrm{Fe}^{2+}-\mathrm{H}_{2} \mathrm{O}_{2}\right)$ adducts in acidic media leads to desorption of $\mathrm{H}_{2} \mathrm{O}_{2}$ into the bulk electrolyte.

Figure 5(c) shows the ring current due to peroxide oxidation measured during ORR in both acidic and alkaline electrolytes. Clearly, the peroxide yield during ORR on FeTPP/C (pyrolyzed at $800^{\circ} \mathrm{C}$ ) is higher in acidic media by an order of magnitude compared to that in alkaline media. This observation is opposite to what was observed on the $\mathrm{Pt} / \mathrm{C}$ and $\mathrm{Ru} / \mathrm{C}$ catalysts discussed previously. The onset potential for ORR in $0.1 \mathrm{M} \mathrm{NaOH}$ is $0.95 \mathrm{~V}$ versus RHE, whereas the corresponding peroxide oxidation current does not begin until $0.8 \mathrm{~V}$. In $0.1 \mathrm{M} \mathrm{HClO}_{4}$, the onset potential for both ORR and peroxide oxidation is $0.8 \mathrm{~V}$. This is further proof for the instability of peroxide intermediate on the active site in acidic media because the weak binding of the $\mathrm{H}_{2} \mathrm{O}_{2}$ intermediate on the $\mathrm{Fe}^{2+}$ active site facilitates its desorption and/or decomposition into the bulk electrolyte. This desorption of $\mathrm{H}_{2} \mathrm{O}_{2}$ into the bulk electrolyte due to its weak binding on the active site is the primary source of peroxide detected at the ring in acidic media. At very high overpotentials $(<0.3 \mathrm{~V})$, the ORR process in acidic electrolyte becomes very efficient and consequently the peroxide detected decreases $[71,72]$. The ring current profile in $0.1 \mathrm{M} \mathrm{NaOH}$ is more complex. Briefly, in alkaline media, the peak in ring current at $0.50 \mathrm{~V}$ is due to the carbon support and the increase in ring current below $0.3 \mathrm{~V}$ is due to reorientation of the water molecules [60, 73]. More importantly, a weak shoulder in the ring current in $0.1 \mathrm{M} \mathrm{NaOH}$ is observed between $0.6 \mathrm{~V}$ and $0.7 \mathrm{~V}$. Also shown in Figure 5(c) is the ring current profile of $\mathrm{Pt} / \mathrm{C}$ for comparison. As discussed previously, the ring current peak due to $\mathrm{Pt} / \mathrm{C}$ around 0.80 to $0.90 \mathrm{~V}$ is the signature for the peroxide formation via outer-sphere electron transfer mechanism at $-\mathrm{OH}$-covered $\mathrm{Pt}$ sites. On $\mathrm{Fe}-\mathrm{N}_{x}$-based catalyst, only a weak shoulder in ring current at more negative potentials of 0.60 to $0.70 \mathrm{~V}$ is observed indicating that the outer-sphere electron transfer mechanism is significantly muted. This indicates the facilitation of direct adsorption of $\mathrm{O}_{2}$ on the $\mathrm{Fe}^{2+}$ active site. This is because the specifically adsorbed $\mathrm{OH}^{-}$species on the $\mathrm{Fe}^{2+}$ site acts as a labile ligand that is easily displaced by the molecular $\mathrm{O}_{2}$. This is ensued by the successful $4 \mathrm{e}^{-}$reduction of $\mathrm{O}_{2}$ with minimal occurrence of outer-sphere electron transfer mechanism.

The nature of the active site obtained upon pyrolysis and the fundamental origin of the activity is investigated here in detail. Figure 6(a) shows the square wave voltammetry (SWV) of non-heat-treated $\mathrm{Fe}(\mathrm{III}) \mathrm{TPPCl} / \mathrm{C}$ in 


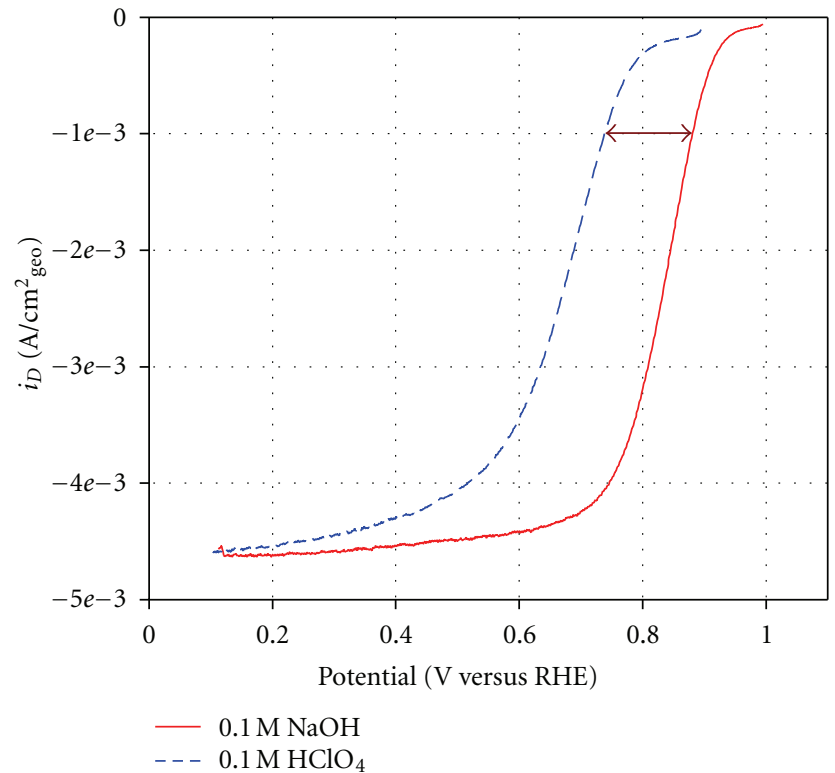

(a) ORR Polarization Curves

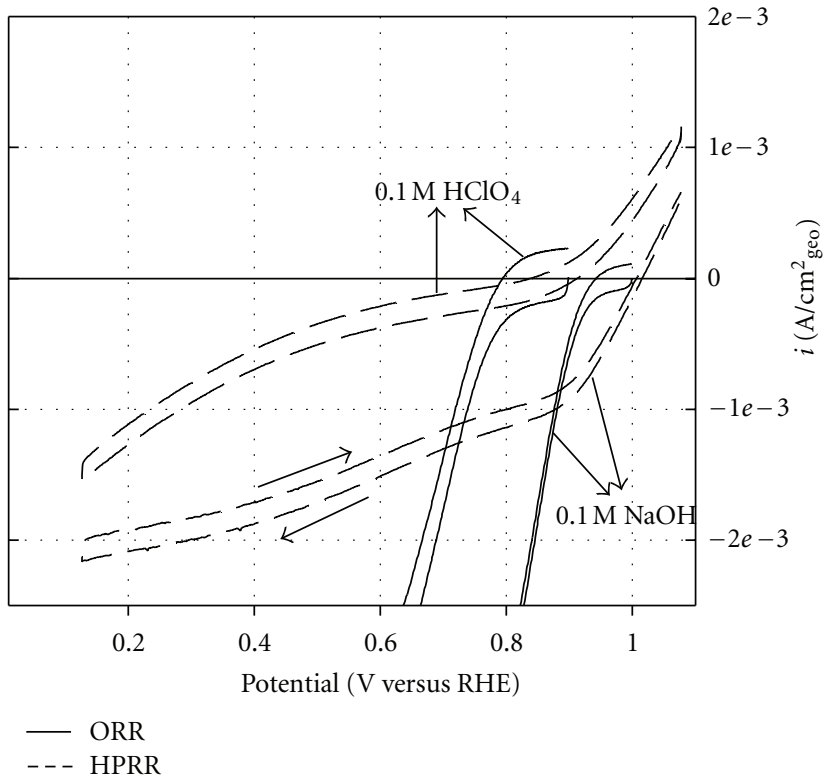

(b) $\mathrm{H}_{2} \mathrm{O}_{2}$ Reduction Reaction (HPRR)

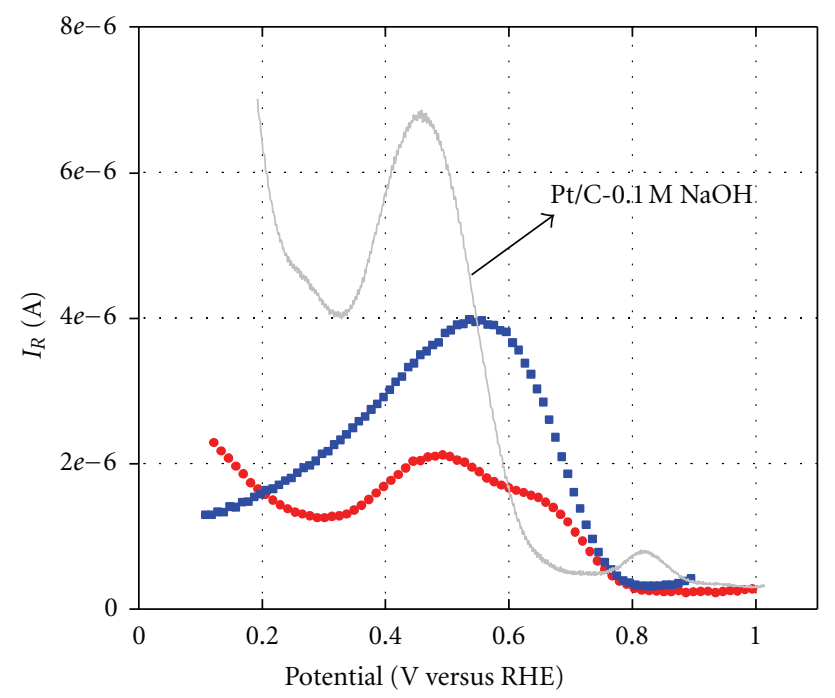

- $0.1 \mathrm{M} \mathrm{NaOH}$

- $0.1 \mathrm{M} \mathrm{HClO}_{4}$

(c) Ring Current

FIGURE 5: ORR activity of FeTPP/C catalyst (pyrolyzed at $800^{\circ} \mathrm{C}$ ) in $\mathrm{O}_{2}$ saturated acidic and alkaline electrolytes. (a) ORR polarization curves, (b) hydrogen peroxide reduction reaction (HPRR) in comparison to ORR, and (c) ring current. All measurements were performed at $900 \mathrm{rpm}$ rotation rate and $20 \mathrm{mV} / \mathrm{s}$ scan rate. $E_{\text {Ring }}=1.1 \mathrm{~V}$ versus $\mathrm{RHE}$ in $0.1 \mathrm{M} \mathrm{NaOH}$ and $E_{\text {Ring }}=1.3 \mathrm{~V}$ versus $\mathrm{RHE}$ in $0.1 \mathrm{M} \mathrm{HClO}$. HPRR is shown in oxygen-free electrolytes containing externally added $\mathrm{H}_{2} \mathrm{O}_{2}$ at a concentration of $3.5 \mathrm{mM}$. Also shown in (c) is the ring current profile of $30 \% \mathrm{Pt} / \mathrm{C}$ in $0.1 \mathrm{M} \mathrm{NaOH}$ for comparison.

argon-saturated $0.1 \mathrm{M} \mathrm{NaOH}$ and $0.1 \mathrm{M} \mathrm{HClO}_{4}$ electrolytes, and Figure 6(b) shows the corresponding CV. As seen in both the SWV and the CV profiles, the redox transition involving the metal center $\mathrm{Fe}^{2+/ 3+}$ is observed at $0.314 \mathrm{~V}$ versus RHE in $0.1 \mathrm{M} \mathrm{NaOH}$ and at $0.155 \mathrm{~V}$ versus RHE in $0.1 \mathrm{M} \mathrm{HClO}_{4}$ $[30,31,74]$. As seen in the SWV profile, the peaks at $1.260 \mathrm{~V}$ in $0.1 \mathrm{M} \mathrm{HClO}_{4}$ and $1.508 \mathrm{~V}$ in $0.1 \mathrm{M} \mathrm{NaOH}$ correspond to the one-electron redox transition involving the delocalized $\pi$-electron system in the macrocycle ligand [74]. As observed in the literature [30], CV of the heat-treated catalysts does not yield useful information, since in most cases after heat treatment the double-layer charging current overwhelms the Faradaic currents. In order to overcome this limitation, SWV was performed as shown in Figure 7 in order to understand the evolution of the active site in these catalysts with increasing heat treatment temperatures. Figures 7(a) 


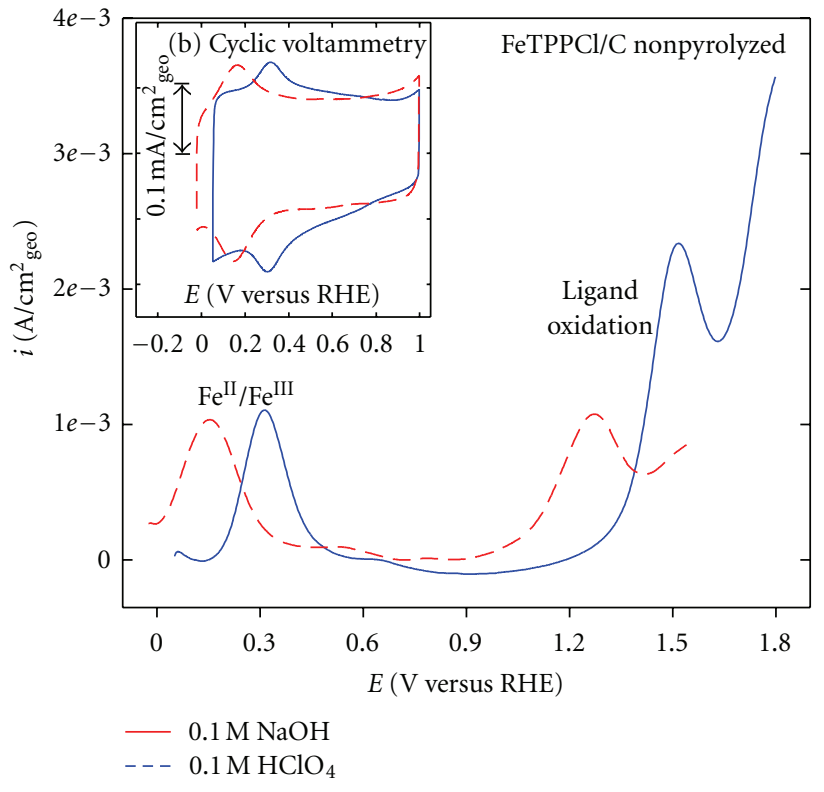

(a) Square wave voltammetry

Figure 6: (a) Square wave voltammetry (SWV) and (b) cyclic voltammetry $(\mathrm{CV})$ of as-received iron(III) meso-tetraphenylporphyrin chloride (FeTPPCl/C) supported on Black Pearl carbon. Experiments were performed in argon-saturated $0.1 \mathrm{M} \mathrm{NaOH}$ and $0.1 \mathrm{M} \mathrm{HClO}_{4}$ electrolytes. SWV parameters: $5 \mathrm{mV}$ step potential, $20 \mathrm{mV}$ amplitude, and $10 \mathrm{~Hz}$ frequency. CV: $20 \mathrm{mV} / \mathrm{s}$.

and 7(b) are divided into two panels each due to different potential ranges that are required for baseline correction of SWV profiles. As seen in Figure 7(a) in alkaline media, after $300^{\circ} \mathrm{C}$ pyrolysis, the $\mathrm{Fe}^{2+/ 3+}$ redox couple at $0.31 \mathrm{~V}$ and the ligand oxidation peak at $1.5 \mathrm{~V}$ are similar to the case of non-heat-treated catalyst. After heat treatment at $500^{\circ} \mathrm{C}$ and $600^{\circ} \mathrm{C}$, the magnitude of the peak currents decrease significantly due to the sublimation of some fraction of the metal macrocycle complex. More importantly, the $\mathrm{Fe}^{2+/ 3+}$ peak potentials have shifted to more anodic potentials. As seen in Panel 1 of Figure 7(a), after pyrolysis at $500^{\circ} \mathrm{C}$ and $600^{\circ} \mathrm{C}$, the peak potential $\left(E_{p}\right)$ of the $\mathrm{Fe}^{2+/ 3+}$ couple has shifted to $0.405 \mathrm{~V}$ and $0.427 \mathrm{~V}$, respectively. Correspondingly, the ligand oxidation peak at $\sim 1.5 \mathrm{~V}$, shown in Panel 2 of Figure 7(a), decreases in magnitude significantly due to the sublimation and/or destruction of the macrocycle. The ligand oxidation peak is not observed after heat treatment at temperatures greater than $600^{\circ} \mathrm{C}$ indicating that the delocalized $\pi$-electron system of the macrocycle does not survive such high temperatures on the carbon support. After $800^{\circ} \mathrm{C}$ pyrolysis, $\mathrm{Fe}^{2+/ 3+}$ couple has shifted more anodically to $E_{p}=0.48 \mathrm{~V}$. As shown in Figure 7(a) (Panel 2), the most interesting observation is that after pyrolysis at $600^{\circ} \mathrm{C}$ a new shoulder begins to emerge at $\sim 1.2 \mathrm{~V}$. This shoulder resolves into a clear peak after $800^{\circ} \mathrm{C}$ pyrolysis with a peak potential of $1.25 \mathrm{~V}$ versus RHE in alkaline media. This new peak is attributed to an anodic shift in the $\mathrm{Fe}^{2+/ 3+}$ redox couple based on the in situ XANES experimental results shown later (vide infra). This indicates the presence of two $\mathrm{Fe}^{2+/ 3+}$ redox couples, one at a low potential $(\sim 0.48 \mathrm{~V})$ and another at a high potential $(1.25 \mathrm{~V})$. The anodic shift in $\mathrm{Fe}^{2+/ 3+}$ redox peak potentials shown in Figure 7(a) (inset) clearly indicates that after $600^{\circ} \mathrm{C}$ pyrolysis the metal center exists in two redox environments. Qualitatively, similar behavior was observed in acidic media as shown in Figure 7(b). (Note that the ligand oxidation peak in acidic media that occurs above $1 \mathrm{~V}$ versus RHE is not shown in Panel 2 of Figure 7(b).) It is interesting to note that after heat treatment at $600^{\circ} \mathrm{C}$ the $\mathrm{Fe}^{2+/ 3+}$ redox peak potential in $0.1 \mathrm{M} \mathrm{HClO}_{4}$ was shifted to an anodic potential of only $0.80 \mathrm{~V}$ versus RHE compared to the $1.25 \mathrm{~V}$ in alkaline media. Thus, there are two reasons for the lower ORR overpotential for FeTPP/C catalyst in alkaline media: (1) the higher redox potential of the $\mathrm{Fe}^{2+/ 3+}$ metal center in alkaline media and (2) the improved stability of the peroxide intermediate on the active site. This translates into efficient $4 \mathrm{e}^{-}$ORR reaction with lower overpotential in alkaline media compared to acidic media.

3.3.1. Delta-Mu $(\Delta \mu)$ Studies. Both the extended X-ray absorption fine structure (EXAFS) and X-ray absorption near edge structure (XANES) being bulk averaged techniques overlook the critical electrochemical reactions occurring on the catalyst surface. Delta-mu $(\Delta \mu)$ is a surface sensitive, spectral subtraction technique, where the bulk structure of the catalyst is effectively removed leading to information on the nature and site specificity of the surface adsorbates [54, $55,75,76]$. Figure 8 (a) shows the XANES region of FeTPP/C catalyst pyrolyzed at $300^{\circ} \mathrm{C}$ taken at two different potentials of $0.1 \mathrm{~V}$ and $0.9 \mathrm{~V}$ versus RHE. At $0.1 \mathrm{~V}$, the metal center exists in the reduced $\mathrm{Fe}^{2+}$ state with no adsorbates (neither hydrides nor oxides) at the axial position, and immediate coordination environment is reminiscent of the iron(II) phthalocyanine complex, where the preedge peak is muted. At $0.9 \mathrm{~V}$, the metal center is oxidized to $\mathrm{Fe}^{3+}$ state with an oxygen atom at the axial position, and the metal coordination environment is similar to that of the original porphyrin complex, where the preedge $\mathrm{Fe}(1 \mathrm{~s} \rightarrow 3 \mathrm{~d})$ forbidden transition at $7112.5 \mathrm{eV}$ is observed. The delta-mu spectra is obtained by subtracting the XANES regions according to the equation $\Delta \mu=\mu(0.90 \mathrm{~V})-\mu(0.10 \mathrm{~V})$. In the delta-mu spectra of Figure $8(\mathrm{a})$, the positive peak feature (boxed portion) indicates the difference in absorption probability at the preedge energy $(7112.5 \mathrm{eV})$. This positive peak feature could be safely assigned as a signature for the existence of the metal center in a centrosymmetric environment undergoing a transition from $\mathrm{Fe}^{2+}-\mathrm{N}_{4}$ coordination geometry at $0.10 \mathrm{~V}$ to $\mathrm{O}-\mathrm{Fe}^{3+}-\mathrm{N}_{4}$ coordination geometry at $0.90 \mathrm{~V}$. Ensuing this positive peak is a steep negative dip featuring a split peak below $20 \mathrm{eV}$. This negative dip characterizes charge transfer from the metal center to the adsorbed oxygen species [77]. As shown in Figure $8(\mathrm{~b})$, the XANES spectra of the $800^{\circ} \mathrm{C}$ pyrolyzed catalyst is predominantly characteristic of metallic iron at both $0.10 \mathrm{~V}$ and $1.10 \mathrm{~V}$ that precludes proper analysis of the active site. However, careful analysis of the corresponding delta-mu spectra clearly indicates the positive peak feature at the preedge energy indicative of the fact that the active site is $\mathrm{Fe}^{2+}-\mathrm{N}_{4}$ where the metal center is in a centrosymmetric environment which is mildly disrupted by the presence of 


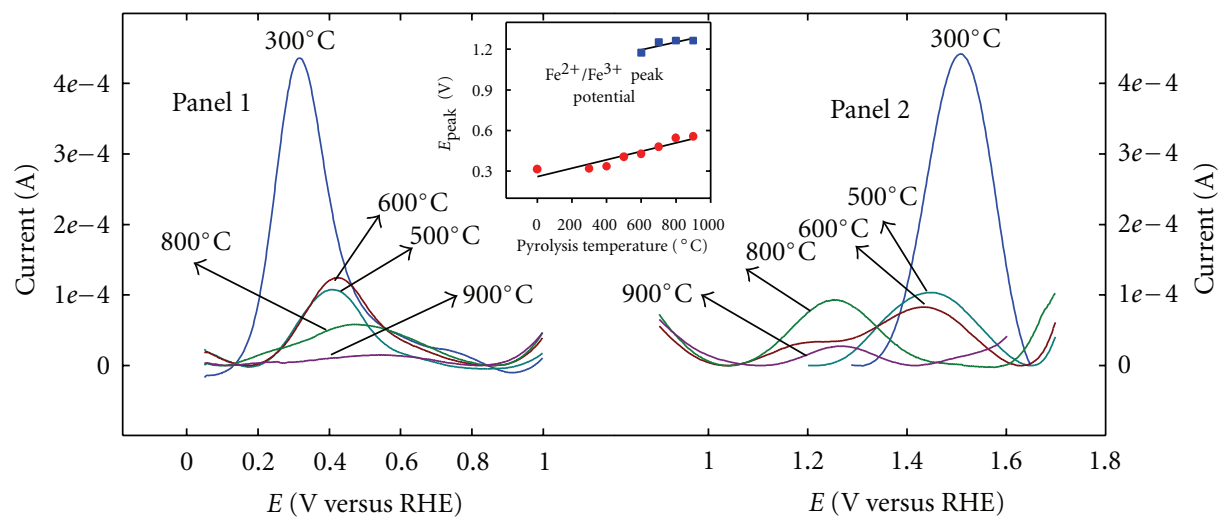

(a) Square wave voltammetry in $0.1 \mathrm{M} \mathrm{NaOH}$

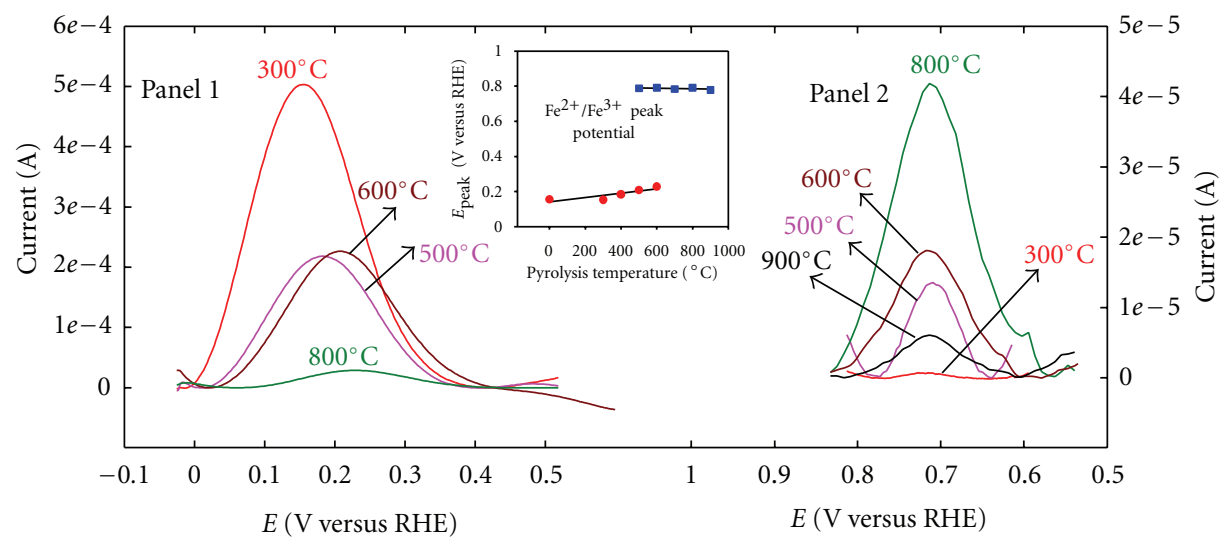

(b) Square wave voltammetry in $0.1 \mathrm{M} \mathrm{HCIO}_{4}$

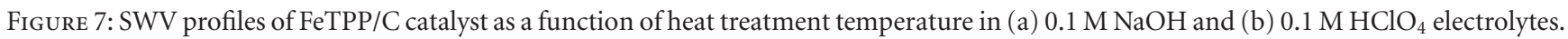
Insets show the peak potential of the $\mathrm{Fe}^{2+/ 3+}$ redox couple as a function of the heat treatment temperature. SWV experiment parameters: step potential $-5 \mathrm{mV}$, amplitude $-20 \mathrm{mV}$, and scan frequency $-10 \mathrm{~Hz}$.

an axial oxygen atom. This clearly indicates that the $\mathrm{Fe}^{2+}$ metal center surrounded by four nitrogen atoms is the active site that binds oxygen in the axial position and the redox transition from $\mathrm{Fe}^{3+}$ to $\mathrm{Fe}^{2+}$ triggers oxygen adsorption according to the redox mechanism [78]. Figure 9 shows the theoretical delta-mu $\left(\Delta \mu_{t}\right)$ spectra obtained using FEFF8.0 code [56]. The structural models used are shown in the insets of Figure 9. Only the atoms encircled were used in the theoretical FEFF8.0 modeling. These theoretical spectra were calculated from $\mathrm{Fe}-\mathrm{N}_{4}-\mathrm{C}_{x}$ models derived from prior crystallographic data adjusted to the EXAFS fitting results according to the relation $\Delta \mu_{t}=\mu\left(\mathrm{O}_{\mathrm{ads}}-\mathrm{Fe}-\mathrm{N}_{4}-\mathrm{C}\right)-\mu\left(\mathrm{Fe}-\mathrm{N}_{4^{-}}\right.$ $\mathrm{C})$, where the oxide species $\left(\mathrm{O}_{\mathrm{ads}}\right.$ or $\left.\mathrm{OH}_{\mathrm{ads}}\right)$ is in a specific binding site. In all cases, the positive peak feature at the preedge energy was observed only when the adsorbed oxygen atom was placed in the axial position of the metal center. No successful theoretical delta-mu fits could be obtained for $\mathrm{Fe}-\mathrm{N}$ coordination numbers less than four or for oxygen adsorption modes other than at the axial position. As shown in the inset of Figure $9(\mathrm{a})$, after $300^{\circ} \mathrm{C}$ pyrolysis the immediate coordination environment of the original precursor porphyrin macrocycle is clearly retained. This corresponds to an $\mathrm{FeN}_{4} \mathrm{C}_{12}$ cluster, where the metal center is coordinated to four nitrogen atoms and each nitrogen atom in turn bonded to two carbon atoms. Finally, inclusion of the four methine carbon bridges gives a tally of $\mathrm{C}_{12}$. Figure 9(b) shows the theoretical delta-mu spectrum that likely mimics the line shape of the experimental delta-mu shown in Figure 8 (b) for the $800^{\circ} \mathrm{C}$ heat-treated catalyst. As shown in the inset of Figure 9(b), the molecular cluster used to simulate the theoretical delta-mu spectrum consisted of $\mathrm{FeN}_{4} \mathrm{C}_{10}$. While compositionally this cluster is not very different from the $300^{\circ} \mathrm{C}$ pyrolyzed sample, the immediate coordination environment of the metal active site after $800^{\circ} \mathrm{C}$ heat treatment is found to be reminiscent of the crystallographic atomic defects such as the divacancy on the graphitic surfaces. This is schematically depicted in Figure 9 (c) $[79,80]$. Atomic defects such as monovacancy and divacancy on microporous carbon and carbon nanotubes are known to thermodynamically exist or can be induced via various chemical or physical processes [81-85]. The presence of a monovacancy in carbon atom creates three dangling bonds whereas divacancies create four dangling bonds. These dangling bonds give rise to unsaturated valences that then become favorable for nitrogen doping [80]. Consequently, these nitrogen-doped sites constitute defective pockets for metal coordination. Such atomic vacancies are either already present on the graphite surfaces or can be created during the 


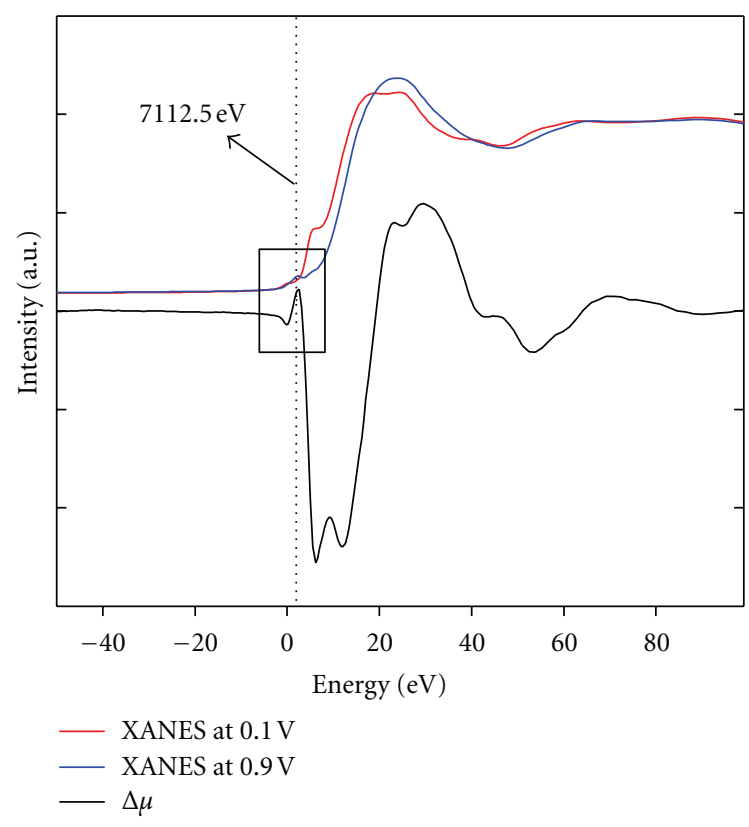

(a) $300^{\circ} \mathrm{C}$ Pyrolysis

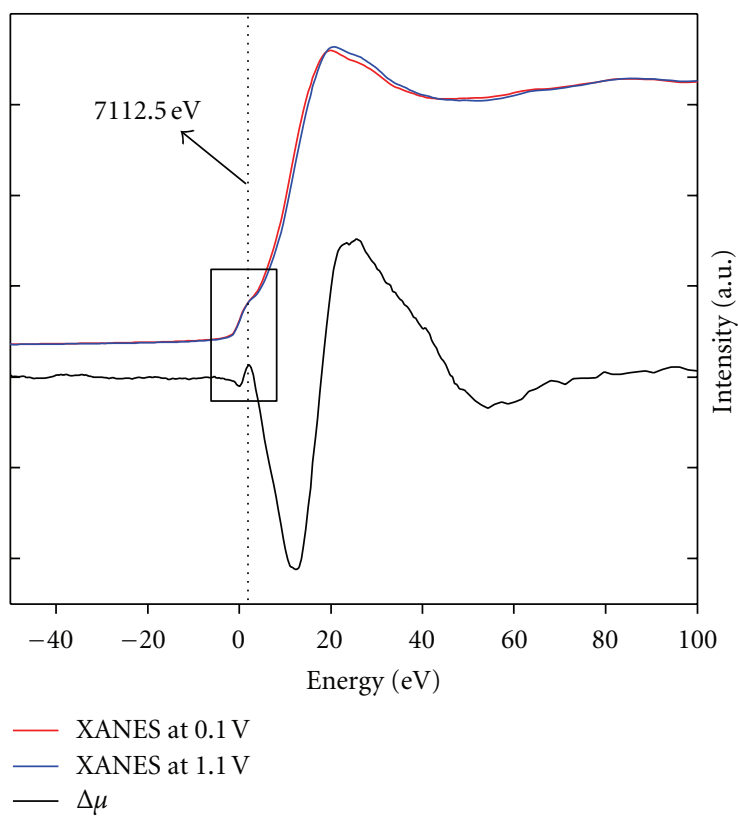

(b) $800^{\circ} \mathrm{C}$ Pyrolysis

FIGURE 8: Experimental XANES and delta-mu signatures of FeTPP/C catalyst heat treated at (a) $300^{\circ} \mathrm{C}$ and (b) $800^{\circ} \mathrm{C}$. Delta-mu signatures were obtained by subtracting the XANES signatures according to $\Delta \mu=\mu(0.90$ (or) $1.10 \mathrm{~V})-\mu(0.10 \mathrm{~V}$ ). Experiments were conducted at Fe K-edge under in situ conditions in argon-saturated $0.1 \mathrm{M} \mathrm{NaOH}$ electrolyte. Vertical dotted line indicates the preedge position at $7112.5 \mathrm{eV}$ and the boxed region focuses the preedge region. Delta-mu spectra have been multiplied by a factor of 5 for visual comparison of the line shapes.

heat treatment step $[81,83]$. During heat treatment under inert atmosphere, carbothermic reaction causes desorption of oxygen functional groups along with creation of vacancy defects [83]. It has also been observed earlier that heattreated Fe- $\mathrm{N}_{x}$ catalysts showed higher activity when supported on carbon that was previously treated in concentrated inorganic acids [52]. Since such acid treatment steps lead to oxygen functional groups on carbon support, it is likely that this yields higher number of defective sites during subsequent heat treatment. These defective pockets are likely the favorable zones for anchoring $\mathrm{FeN}_{4}$ active sites. Presumably, the low concentration of the defective sites limits the active site density. Therefore, increasing the defect density likely holds key to increasing the metal loading in this class of catalysts.

The following observations are made in an attempt to correlate the SWV and the delta-mu results. The lowpotential $\mathrm{Fe}^{2+/ 3+}$ redox couple is characteristic of the original $\mathrm{FeN}_{4}$ porphyrin moiety, whereas the high-potential $\mathrm{Fe}^{2+/ 3+}$ redox couple is characteristic of the $\mathrm{FeN}_{4}$ cluster found in the microporous carbon defect sites. At a pyrolysis temperature of $600^{\circ} \mathrm{C}$, both of these sites seem to coexist and the higher ORR activity obtained for heat treatment temperatures $\geq 600^{\circ} \mathrm{C}$ is due to the high-potential $\mathrm{Fe}^{2+/ 3+}$ redox couple seated in the defective pockets. Based on the above experimental results, the following reaction scheme is proposed for ORR in dilute alkaline media on heat-treated FeTPP/C catalyst. Similar set of reactions can be developed, mutatis mutandis, for dilute acidic media $[22,71,72,86]$. Equation
(9) shows the redox reaction involving the metal center that is a prerequisite for adsorption of molecular oxygen on the active site $\left[\mathrm{N}_{4}-\mathrm{Fe}^{\mathrm{II}}-\mathrm{OH}^{-}\right]$:

$$
\left[\mathrm{N}_{4}-\mathrm{Fe}^{\mathrm{III}}-\mathrm{OH}\right]+\mathrm{e}^{-} \longrightarrow\left[\mathrm{N}_{4}-\mathrm{Fe}^{\mathrm{II}}\right]+\mathrm{OH}^{-}
$$

While the $\mathrm{Fe}^{\mathrm{II}}$ valence state favors a square-planar tetracoordinate environment, the high potential of this redox reaction causes the $\mathrm{OH}^{-}$species to poison the active site at the axial position. This poisonous $\mathrm{OH}^{-}$species prevents direct molecular adsorption of $\mathrm{O}_{2}$ on the active site. Further, the adsorbed $\mathrm{OH}^{-}$species mediates the $2 \mathrm{e}^{-}$outer-sphere electron transfer reduction of solvated $\mathrm{O}_{2}$ molecule as shown in the reaction schemes (3)-(5) although this outer-sphere mechanism appears to be extremely weak in this class of pyrolyzed catalysts as explained previously. It should be noted that the case of outer-sphere mechanism does not arise in acidic media for reasons explained previously.

Finally, the $4 \mathrm{e}^{-}$electrocatalytic inner-sphere electron transfer mechanism is shown in Figure 10, where the molecular $\mathrm{O}_{2}$ displaces the $\mathrm{OH}^{-}$species and chemisorbs directly on the $\mathrm{Fe}^{\mathrm{II}}$ active site. Based on our experimental results, the electrocatalytic process in Figure 10 is shown to take place via a redox mechanism involving $\mathrm{Fe}^{\mathrm{II} / \mathrm{III}}$ couple [78]. Once molecular $\mathrm{O}_{2}$ adsorbs on the $\mathrm{Fe}^{\mathrm{II}}$ active site, the reaction proceeds to the ferrous-hydroperoxyl adduct via the superoxo and the ferric-hydroperoxyl states. The ferrous-hydroperoxyl adduct is very critical since its stability determines the product distribution. Peroxide anion $\left(\mathrm{HO}_{2}{ }^{-}\right)$ is a stable intermediate. So, weak binding of $\mathrm{HO}_{2}{ }^{-}$on the 


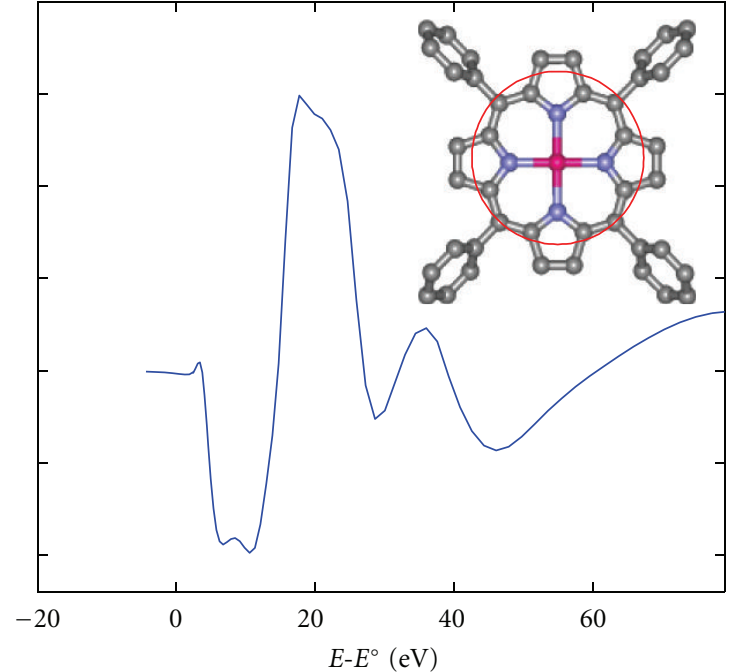

(a) $300^{\circ} \mathrm{C}$ Pyrolysis

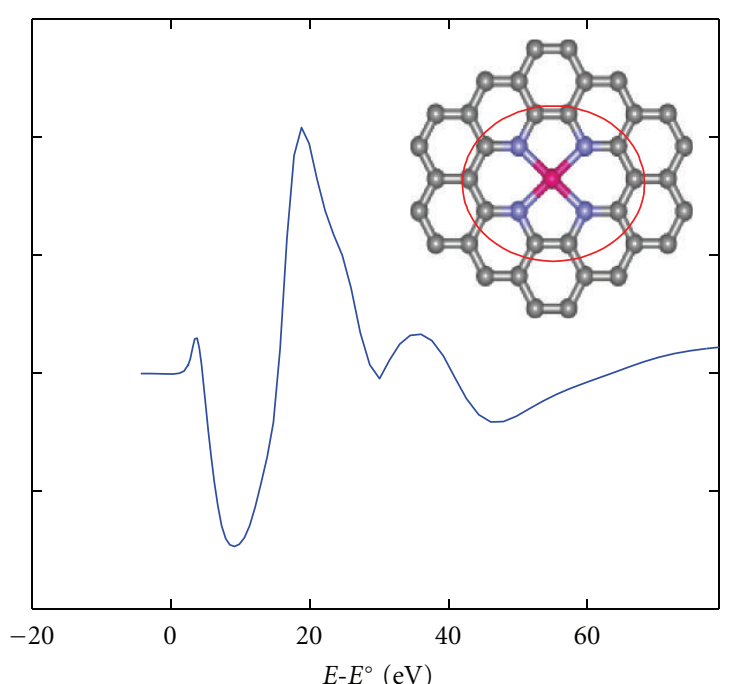

(b) $800^{\circ} \mathrm{C}$ Pyrolysis

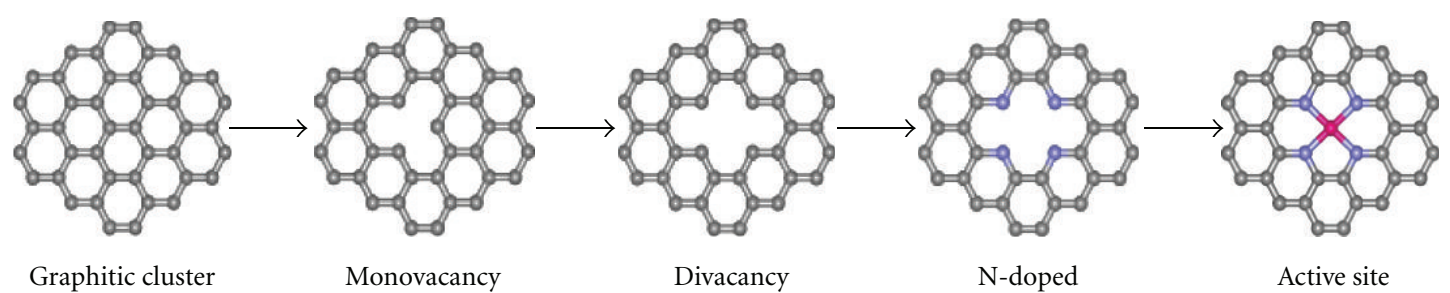

(c)

Figure 9: Theoretical FEFF8 $\Delta \mu=\mu\left(\mathrm{Fe}-\mathrm{N}_{4}-\mathrm{C}_{x}-\mathrm{O}_{\mathrm{ads}}\right)-\mu\left(\mathrm{Fe}-\mathrm{N}_{4}-\mathrm{C}_{x}\right)$ signatures obtained for (a) $300^{\circ} \mathrm{C}$ and (b) $800^{\circ} \mathrm{C}$ pyrolysis conditions. The insets in $(\mathrm{a}, \mathrm{b})$ show the corresponding structural models utilized. Only the atoms encircled in these structural models were used for FEFF8 simulation. (c) Schematic illustration of the mono- and divacant defective pockets in amorphous carbon acting as anchors for active site formation during pyrolysis. Color codes: pink: Fe, blue: $\mathrm{N}$, and black: C.

active site will lead to its desorption into the bulk electrolyte. As mentioned previously, the stable acid-base adduct formed in alkaline media stabilizes the ferrous-hydroperoxyl adduct. This ensures that the catalytic cycle shown in Figure 10 regenerates the active site via the formation of ferrichydroxyl species. However, in acidic media the analogous ferrous-hydrogen peroxide adduct $\mathrm{Fe}^{\mathrm{II}}-(\mathrm{OHOH})$ is unstable and causes desorption and/or disproportionation of the peroxide intermediate $\left(\mathrm{H}_{2} \mathrm{O}_{2}\right)$ into the bulk electrolyte. This leads to higher peroxide yield in acidic media as shown previously.

\section{Conclusions}

The case of ORR in alkaline media shows interesting mechanistic differences compared to acidic media. In acidic media, the presence of $\mathrm{OH}_{\mathrm{ad}}$ due to water activation blocks the direct adsorption of molecular $\mathrm{O}_{2}$ on the active site. In alkaline media, the presence of $\mathrm{OH}_{a d}$ due to specific adsorption of hydroxide species not only blocks the $\mathrm{O}_{2}$ adsorption but also promotes outer-sphere electron transfer mechanism to yield the $2 \mathrm{e}^{-}$peroxide intermediate as the product. The interaction between the $\mathrm{O}_{2} \cdot\left(\mathrm{H}_{2} \mathrm{O}\right)_{n}$ cluster and the surface hydroxyl species causes certain nonspecificity to the identity of the underlying electrode metal. This nonspecificity is a result of kinetic differences in alkaline media that opens the gate to use a wide-range of nonnoble metals and their oxides as electrode materials, while in acidic media the absence of this outer-sphere mechanism necessitates the use of highly catalytic surfaces based on Pt. On noble metals such as $\mathrm{Pt}$, this nonspecificity in alkaline media is observed only in the oxide formation region, and depending on the extent of $\mathrm{OH}_{\mathrm{ad}}$ coverage both inner- and outer-sphere electron transfer mechanisms coexist in alkaline media. On nonnoble metals such as the first-row transition elements that are completely passivated by a layer oxide film upon immersion into the aqueous electrolyte, this outersphere electron transfer process is likely to be the dominant mechanism. While the outer-sphere mechanism primarily seems to yield peroxide intermediate as the final product, this could be beneficial in cases like $\mathrm{Ru} / \mathrm{C}$ catalyst, where the peroxide intermediate generated in the outersphere process could be readsorbed on the oxide-free $\mathrm{Ru}$ site to reduce further to form hydroxide as the final product. However, in cases like nonnoble metal surfaces, where the electrode surface is incapable of reducing peroxide intermediate any further, only $2 \mathrm{e}^{-}$reduction products are likely to predominate in alkaline media. So, it is important to promote the inner-sphere electron transfer mechanism in alkaline media by facilitating the direct molecular 




FIGURE 10: Catalytic cycle showing the redox mechanism involved in ORR on heat-treated iron porphyrin macrocycles in dilute alkaline medium. Nitrogen atoms in the square planar positions have been omitted for clarity.

$\mathrm{O}_{2}$ adsorption and promoting complete $4 \mathrm{e}^{-}$reduction process.

On catalyst surfaces such as the $\mathrm{Fe}-\mathrm{N}_{4}$ systems, the operation of redox mechanism allows the direct molecular $\mathrm{O}_{2}$ adsorption on the $\mathrm{Fe}^{2+}-\mathrm{N}_{4}$ active site and prevents the precipitous outer-sphere reaction of solvated $\mathrm{O}_{2}$ molecule with the $\mathrm{OH}_{\mathrm{ad}}$-covered metal site. This is due to the $\mathrm{OH}_{\mathrm{ad}}$ species acting as a labile ligand in the $\mathrm{Fe}-\mathrm{N}_{4}$-based catalysts that helps to promote the $4 \mathrm{e}^{-}$inner-sphere electron transfer mechanism by efficiently reducing $\mathrm{O}_{2}$ to $\mathrm{OH}^{-}$in alkaline media. Further, in the class of $\mathrm{Fe}-\mathrm{N}_{4}$-based catalysts, it is important to perform ORR studies with a thin film of catalyst surface $(\leq 25 \mu \mathrm{m})$ rather than thick catalyst films that are typically used in the literature, where the peroxide formed is completely quenched within the catalyst layer and hence not being detected at the ring electrode. This is especially true while Koutecky-Levich plots for calculating the number of electrons transferred since such calculations were derived for smooth electrode surfaces. Also, it is noted that if a catalyst is considered to perform $4 \mathrm{e}^{-}$oxygen reduction, then it is imperative to show the reduction of externally added hydrogen peroxide in the absence of $\mathrm{O}_{2}$. Finally, in conclusion, the presence of the outer-sphere electron transfer mechanism in alkaline media is a kinetic effect. The only thermodynamic advantage of performing ORR at high $\mathrm{pH}$ is the improved stability of the hydroperoxide anion intermediate on the active site that enables complete $4 \mathrm{e}^{-}$transfer. So, in order to stabilize the $\mathrm{H}_{2} \mathrm{O}_{2}$ intermediate in acidic media, the use of dimeric active sites that simultaneously bind both oxygen atoms are required.

\section{Acknowledgments}

The authors deeply appreciate financial assistance from the Army Research Office under the Single Investigator Grant. The authors also gratefully acknowledge the supply of platinum electrocatalysts from BASF fuel cells (Somerset,
NJ, USA). Use of the National Synchrotron Light Source (NSLS) at Brookhaven National Laboratory (BNL) was supported by the US Department of Energy, Office of Basic Energy Sciences. Support from NSLS beamline personnel Drs. Kaumudi Pandya (X11A), Syed Khalid (X19A), and Nebojsa Marinkovic (X18B) is gratefully acknowledged.

\section{References}

[1] J. S. Spendelow and A. Wieckowski, "Electrocatalysis of oxygen reduction and small alcohol oxidation in alkaline media," Physical Chemistry Chemical Physics, vol. 9, no. 21, pp. 26542675, 2007.

[2] E. Yeager, "Electrocatalysts for $\mathrm{O}_{2}$ reduction," Electrochimica Acta, vol. 29, no. 11, pp. 1527-1537, 1984.

[3] R. Adzic, "Frontiers in electrochemistry," in Electrocatalysis, J. Lipkowski and P. N. Ross, Eds., vol. 197, Wiley-VCH, New York, NY, USA, 1998.

[4] D. B. Sepa, M. V. Vojnovic, and A. Damjanovic, "Kinetics and mechanism of $\mathrm{O}_{2}$ reduction at $\mathrm{Pt}$ in alkaline solutions," Electrochimica Acta, vol. 25, no. 11, pp. 1491-1496, 1980.

[5] D. B. Sepa, M. V. Vojnovic, L. M. Vracar, and A. Damjanovic, "Different views regarding the kinetics and mechanisms of oxygen reduction at Pt and Pd electrodes," Electrochimica Acta, vol. 32, no. 1, pp. 129-134, 1987.

[6] A. Damjanovic, A. Dey, and J. O. M. Bockris, "Kinetics of oxygen evolution and dissolution on platinum electrodes," Electrochimica Acta, vol. 11, no. 7, pp. 791-814, 1966.

[7] E. Yeager, M. Razaq, D. Gervasio, A. Razaq, and D. Tryk, "The electrolyte factor in $\mathrm{O}_{2}$ reduction electrocatalysis," Proceedings of the Electrochemical Society, vol. 92-11, pp. 440-473, 1992.

[8] A. Damjanovic, M. A. Genshaw, and J. O'M Bockris, "Distinction between intermediates produced in main and side electrodic reactions," The Journal of Chemical Physics, vol. 45, no. 11, pp. 4057-4059, 1966.

[9] H. S. Wroblowa, Y.-C. Pan, and G. Razumney, "Electroreduction of oxygen a new mechanistic criterion," Journal of Electroanalytical Chemistry, vol. 69, no. 2, pp. 195-201, 1976. 
[10] N. A. Anastasijević, V. Vesović, and R. R. Adžić, "Determination of the kinetic parameters of the oxygen reduction reaction using the rotating ring-disk electrode. Part I. Theory," Journal of Electroanalytical Chemistry, vol. 229, no. 1-2, pp. 305-316, 1987.

[11] N. A. Anastasijević, V. Vesović, and R. R. Adžić, "Determination of the kinetic parameters of the oxygen reduction reaction using the rotating ring-disk electrode. Part II. Applications," Journal of Electroanalytical Chemistry, vol. 229, no. 1-2, pp. 317-325, 1987.

[12] A. J. Bard, "Inner-sphere heterogeneous electrode reactions. Electrocatalysis and photocatalysis: the challenge," Journal of the American Chemical Society, vol. 132, no. 22, pp. 7559-7567, 2010.

[13] A. J. Bard, R. Parsons, and J. Jordan, Eds., Standard Potentials in Aqueous Solution, 1985.

[14] H. H. Yang and R. L. McCreery, "Elucidation of the mechanism of dioxygen reduction on metal-free carbon electrodes," Journal of the Electrochemical Society, vol. 147, no. 9, pp. 3420 $3428,2000$.

[15] B. B. Blizanac, P. N. Ross, and N. M. Markovic, "Oxygen electroreduction on $\operatorname{Ag}(111)$ : the $\mathrm{pH}$ effect," Electrochimica Acta, vol. 52, no. 6, pp. 2264-2271, 2007.

[16] J. O. Bockris and J. Appleby, "Alkaline Fuel Cells," in Assessment of Research Needs for Advanced Fuel Cells, S. S. Penner, Ed., vol. 11, p. 95, 1986.

[17] A. J. Appleby, "Electrocatalysis," in Comprehensive Treatise of Electrochemistry, B. E. Conway, Ed., vol. 7, pp. 173-239, Plenum, New York, NY, USA, 1983.

[18] R. Jasinski, "A new fuel cell cathode catalyst," Nature, vol. 201, no. 4925, pp. 1212-1213, 1964.

[19] J. H. Zagal, "Metallophthalocyanines as catalysts in electrochemical reactions," Coordination Chemistry Reviews, vol. 119, pp. 89-136, 1992.

[20] "Macrocycles," in Handbook of Fuel Cells-Fundamentals, J. H. Zagal, Ed., pp. 544-554, John Wiley \& Sons, Chichester, UK, 2003.

[21] B. Wang, "Recent development of non-platinum catalysts for oxygen reduction reaction," Journal of Power Sources, vol. 152, no. 1-2, pp. 1-15, 2005.

[22] J.-P. Dodelet, "Oxygen reduction in pem fuel cell conditions: heat- treated non-precious metal-N4 macrocycles and beyond," in N4-Macrocyclic Metal Complexes, J. H. Zagal, F. Bedioui, and J.-P. Dodelet, Eds., p. 83, Springer, Berlin, Germany, 2006.

[23] J. M. Ziegelbauer, T. S. Olson, S. Pylypenko et al., "Direct spectroscopic observation of the structural origin of peroxide generation from Co-based pyrolyzed porphyrins for ORR applications," Journal of Physical Chemistry C, vol. 112, no. 24, pp. 8839-8849, 2008.

[24] K. Artyushkova, S. Levendosky, P. Atanassov, and J. Fulghum, "XPS Structural studies of nano-composite non-platinum electrocatalysts for polymer electrolyte fuel cells," Topics in Catalysis, vol. 46, no. 3-4, pp. 263-275, 2007.

[25] A. L. Bouwkamp-Wijnoltz, W. Visscher, and J. A. R. van Veen, "The selectivity of oxygen reduction by pyrolysed iron porphyrin supported on carbon," Electrochimica Acta, vol. 43, no. 21-22, pp. 3141-3152, 1998.

[26] A. L. Bouwkamp-Wijnoltz, W. Visscher, J. A. R. van Veen, E. Boellaard, A. M. van der Kraan, and S. C. Tang, "On active-site heterogeneity in pyrolyzed carbon-supported iron porphyrin catalysts for the electrochemical reduction of oxygen: an in situ mössbauer study," Journal of Physical Chemistry B, vol. 106, no. 50, pp. 12993-13001, 2002.
[27] A. L. Bouwkamp-Wijnoltz, W. Visscher, J. A. R. van Veen, and S. C. Tang, "Electrochemical reduction of oxygen: an alternative method to prepare active $\mathrm{CoN}_{4}$ catalysts," Electrochimica Acta, vol. 45, no. 3, pp. 379-386, 1999.

[28] J. McBreen, W. E. O’Grady, D. E. Sayers, C. Y. Yang, and K. I. Pandya, "An EXAFS study of pyrolyzed metal macrocyclic electrocatalysts," S. Srinivasan, S. Wagner, and H. Wroblowa, Eds., vol. 87-12, p. 182, The Electrochemical Society, Pennington, NJ, USA.

[29] H. Schulenburg, S. Stankov, V. Schünemann et al., "Catalysts for the oxygen reduction from heat-treated iron(III) tetramethoxyphenylporphyrin chloride: structure and stability and active sites," Journal of Physical Chemistry B, vol. 107, no. 34, pp. 9034-9041, 2003.

[30] A. A. Tanaka, S. L. Gupta, D. Tryk, C. Fierro, and E. B. Yeager, "Electrochemical and spectroscopic aspects of heattreated transition metal macrocycles as electrocatalysts for oxygen reduction," in Structural Effects in Electrocatalysis and Oxygen Electrochemistry, D. Scherson, D. Tryk, M. Daroux, and X. Xing, Eds., vol. 92-11, p. 555, Proceedings of the Electrochemical Society, 1992.

[31] I. T. Bae, D. A. Tryk, and D. A. Scherson, "Effect of heat treatment on the redox properties of iron porphyrins adsorbed on high area carbon in acid electrolytes: an in situ Fe K-edge Xray absorption near-edge structure study," Journal of Physical Chemistry B, vol. 102, no. 21, pp. 4114-4117, 1998.

[32] S. Kim, I. T. Bae, M. Sandifer et al., "In situ XANES of an iron porphyrin irreversibly adsorbed on an electrode surface," Journal of the American Chemical Society, vol. 113, no. 24, pp. 9063-9066, 1991.

[33] S. Kim, D. A. Tryk, I. T. Bae et al., "In situ extended X-ray absorption fine structure of an iron porphyrin irreversibly adsorbed on an electrode surface," Journal of Physical Chemistry, vol. 99, no. 25, pp. 10359-10364, 1995.

[34] M. Lefèvre, J. P. Dodelet, and P. Bertrand, "Molecular oxygen reduction in PEM fuel cells: evidence for the simultaneous presence of two active sites in Fe-based catalysts," Journal of Physical Chemistry B, vol. 106, no. 34, pp. 8705-8713, 2002.

[35] M. Lefevre, J. P. Dodelet, and P. Bertrand, "Oi reduction in PEM fuel cells: activity and active site structural information for catalysts obtained by the pyrolysis at high temperature of Fe precursors," Journal of Physical Chemistry B, vol. 104, no. 47, pp. 11238-11247, 2000.

[36] M. Lefèvre and J. P. Dodelet, "Fe-based catalysts for the reduction of oxygen in polymer electrolyte membrane fuel cell conditions: determination of the amount of peroxide released during electroreduction and its influence on the stability of the catalysts," Electrochimica Acta, vol. 48, no. 19, pp. 2749-2760, 2003.

[37] M. Lefèvre, E. Proietti, F. Jaouen, and J. P. Dodelet, "IronBased catalysts with improved oxygen reduction activity in polymer electrolyte fuel cells," Science, vol. 324, no. 5923, pp. 71-74, 2009.

[38] G. Lalande, R. Côté, D. Guay, J. P. Dodelet, L. T. Weng, and P. Bertrand, "Is nitrogen important in the formulation of Febased catalysts for oxygen reduction in solid polymer fuel cells?" Electrochimica Acta, vol. 42, no. 9, pp. 1379-1388, 1997.

[39] G. Lalande, G. Faubert, R. Côté et al., "Catalytic activity and stability of heat-treated iron phthalocyanines for the electroreduction of oxygen in polymer electrolyte fuel cells," Journal of Power Sources, vol. 61, no. 1-2, pp. 227-237, 1996.

[40] M. C. M. Alves, J. P. Dodelet, D. Guay, M. Ladouceur, and G. Tourillon, "Origin of the electrocatalytic properties for $\mathrm{O}_{2}$ reduction of some heat-treated polyacrylonitrile and 
phthalocyanine cobalt compounds adsorbed on carbon black as probed by electrochemistry and X-ray absorption spectroscopy," Journal of Physical Chemistry, vol. 96, no. 26, pp. 10898-10905, 1992.

[41] G. Faubert, R. Côté, J. P. Dodelet, M. Lefèvre, and P. Bertrand, "Oxygen reduction catalysts for polymer electrolyte fuel cells from the pyrolysis of FeII acetate adsorbed on 3,4,9,10perylenetetracarboxylic dianhydride," Electrochimica Acta, vol. 44, no. 15, pp. 2589-2603, 1999.

[42] G. Faubert, G. Lalande, R. Côté et al., "Heat-treated iron and cobalt tetraphenylporphyrins adsorbed on carbon black: physical characterization and catalytic properties of these materials for the reduction of oxygen in polymer electrolyte fuel cells," Electrochimica Acta, vol. 41, no. 10, pp. 1689-1701, 1996.

[43] P. He, M. Lefèvre, G. Faubert, and J. P. Dodelet, "Oxygen reduction catalysts for polymer electrolyte fuel cells from the pyrolysis of various transition metal acetates adsorbed on 3,4,9,10-perylenetetracarboxylic dianhydride," Journal of New Materials for Electrochemical Systems, vol. 2, no. 4, pp. 243$251,1999$.

[44] C. Médard, M. Lefèvre, J. P. Dodelet, F. Jaouen, and G. Lindbergh, "Oxygen reduction by Fe-based catalysts in PEM fuel cell conditions: activity and selectivity of the catalysts obtained with two Fe precursors and various carbon supports," Electrochimica Acta, vol. 51, no. 16, pp. 3202-3213, 2006.

[45] F. Jaouen, E. Proietti, M. Lefèvre et al., "Recent advances in non-precious metal catalysis for oxygen-reduction reaction in polymer electrolyte fuel cells," Energy and Environmental Science, vol. 4, no. 1, pp. 114-130, 2011.

[46] D. P. Amalnerkar, S. Radhakrishnan, H. Minoura, T. Sugiura, and Y. Ueno, "Origin of the photocathodic effect at CdS + $\mathrm{CuCl}$ electrodes," Journal of Electroanalytical Chemistry and Interfacial Electrochemistry, vol. 260, no. 2, pp. 433-440, 1989.

[47] G. Gruenig, K. Wiesener, S. Gamburzev, I. Iliev, and A. Kaisheva, "Investigations of catalysts from the pyrolyzates of cobalt-containing and metal-free dibenzotetraazaannulenes on active carbon for oxygen electrodes in an acid medium," Journal of Electroanalytical Chemistry, vol. 159, no. 1, pp. 155$162,1983$.

[48] J. A. R. van Veen, J. F. van Baar, and K. J. Kroese, "Effect of heat treatment on the performance of carbon-supported transition-metal chelates in the electrochemical reduction of oxygen," Journal of the Chemical Society, Faraday Transactions 1, vol. 77, no. 11, pp. 2827-2843, 1981.

[49] P. Vasudevan, Santosh, N. Mann, and S. Tyagi, "Transition metal complexes of porphyrins and phthalocyanines as electrocatalysts for dioxygen reduction," Transition Metal Chemistry, vol. 15, no. 2, pp. 81-90, 1990.

[50] F. Jaouen, M. Lefèvre, J. P. Dodelet, and M. Cai, "Heattreated $\mathrm{Fe} / \mathrm{N} / \mathrm{C}$ catalysts for $\mathrm{O}_{2}$ electroreduction: are active sites hosted in micropores?" Journal of Physical Chemistry B, vol. 110, no. 11, pp. 5553-5558, 2006.

[51] C. W. B. Bezerra, L. Zhang, K. Lee et al., "A review of Fe$\mathrm{N} / \mathrm{C}$ and $\mathrm{Co}-\mathrm{N} / \mathrm{C}$ catalysts for the oxygen reduction reaction," Electrochimica Acta, vol. 53, no. 15, pp. 4937-4951, 2008.

[52] A. Garsuch, A. Bonakdarpour, G. Liu, R. Yang, and J. R. Dahn, "Time to move beyond transition metal-N-C catalysts for oxygen reduction," in Handbook of Fuel Cells, vol. 5, Springer, New York, NY, USA, 2009.

[53] N. Ramaswamy, R. J. Allen, and S. Mukerjee, "Electrochemical kinetics and X-ray absorption spectroscopic investigations of oxygen reduction on chalcogen-modified ruthenium catalysts in alkaline media," Journal of Physical Chemistry C, vol. 115, no. 25, pp. 12650-12664, 2011.

[54] T. M. Arruda, B. Shyam, J. S. Lawton et al., "Fundamental aspects of spontaneous cathodic deposition of $\mathrm{Ru}$ onto $\mathrm{Pt} / \mathrm{C}$ electrocatalysts and membranes under direct methanol fuel cell operating conditions: an in situ X-ray absorption spectroscopy and electron spin resonance study," Journal of Physical Chemistry C, vol. 114, no. 2, pp. 1028-1040, 2010.

[55] T. M. Arruda, B. Shyam, J. M. Ziegelbauer, S. Mukerjee, and D. E. Ramaker, "Investigation into the competitive and sitespecific nature of anion adsorption on Pt using in situ X-ray absorption spectroscopy," Journal of Physical Chemistry C, vol. 112, no. 46, pp. 18087-18097, 2008.

[56] A. L. Ankudinov, B. Ravel, J. J. Rehr, and S. D. Conradson, "Real-space multiple-scattering calculation and interpretation of x-ray-absorption near-edge structure," Physical Review B, vol. 58, no. 12, pp. 7565-7576, 1998.

[57] V. S. Murthi, R. C. Urian, and S. Mukerjee, "Oxygen reduction kinetics in low and medium temperature acid environment: correlation of water activation and surface properties in supported Pt and Pt alloy electrocatalysts," Journal of Physical Chemistry B, vol. 108, no. 30, pp. 11011-11023, 2004.

[58] M. R. Tarasevich, A. Sadkowski, and E. Yeager, "Kinetics and mechanisms of electrode processes," in Comprehensive Treatise of Electrochemistry, B. E. Conway, J. O. M. Bockris, E. Yeager, S. U. M. Khanand, and R. E. White, Eds., vol. 7, pp. 301-398, Plenum Press, New York, NY, USA, 1983.

[59] N. M. Marković, H. A. Gasteiger, and P. N. Ross, "Oxygen reduction on platinum low-index single-crystal surfaces in alkaline solution: rotating ring diskPt(hkl) studies," Journal of Physical Chemistry, vol. 100, no. 16, pp. 6715-6721, 1996.

[60] N. Ramaswamy and S. Mukerjee, "Influence of inner- and outer-sphere electron transfer mechanisms during electrocatalysis of oxygen reduction in alkaline media," Journal of Physical Chemistry C, vol. 115, no. 36, pp. 18015-18026, 2011.

[61] E. Janin, H. Von Schenck, M. Göthelid, U. O. Karlsson, and M. Svensson, "Bridge-bonded atomic oxygen on $\operatorname{Pt}(110)$," Physical Review B, vol. 61, no. 19, pp. 13144-13149, 2000.

[62] G. Jerkiewicz, G. Vatankhah, J. Lessard, M. P. Soriaga, and Y. S. Park, "Surface-oxide growth at platinum electrodes in aqueous $\mathrm{H}_{2} \mathrm{SO}_{4}$ Reexamination of its mechanism through combined cyclic-voltammetry, electrochemical quartz-crystal nanobalance, and Auger electron spectroscopy measurements," Electrochimica Acta, vol. 49, no. 9-10, pp. 1451-1459, 2004.

[63] N. M. Markoví and P. N. Ross, "Surface science studies of model fuel cell electrocatalysts," Surface Science Reports, vol. 45, no. 4-6, pp. 117-229, 2002.

[64] P. Chen and R. L. McCreery, "Control of electron transfer kinetics at glassy carbon electrodes by specific surface modification," Analytical Chemistry, vol. 68, no. 22, pp. 3958-3965, 1996.

[65] P. Chen, M. A. Fryling, and R. L. McCreery, "Electron transfer kinetics at modified carbon electrode surfaces: the role of specific surface sites," Analytical Chemistry, vol. 67, no. 18, pp. 3115-3122, 1995.

[66] N. Wakabayashi, F. Kitamura, T. Ohsaka, and K. Tokuda, "Effect of adsorbed anions on the outer-sphere electrontransfer reactions of cobalt complexes at platinum singlecrystal electrodes," Journal of Electroanalytical Chemistry, vol. 499, no. 1, pp. 161-168, 2001.

[67] T. Wandlowski and R. de Levie, "Double-layer dynamics in the adsorption of tetrabutylammonium ions at the mercurywater interface Part 4 . The reduction of hexammine-cobalt 
(III) through tetrabutylammonium films," Journal of Electroanalytical Chemistry, vol. 380, no. 1-2, pp. 201-207, 1995.

[68] N. A. Anastasijevic, Z. M. Dimitrijevic, and R. R. Adzic, "Oxygen reduction on a ruthenium electrode in alkaline electrolytes," Journal of Electroanalytical Chemistry and Interfacial Electrochemistry, vol. 199, no. 2, pp. 351-364, 1986.

[69] N. A. Anastasijevic, Z. M. Dimitrijevic, and R. R. Adzic, "Oxygen reduction on a ruthenium electrode in acid electrolytes," Electrochimica Acta, vol. 31, no. 9, pp. 1125-1130, 1986.

[70] N. Ramaswamy, R. J. Allen, and S. Mukerjee, "Electrochemical kinetics and X-ray absorption spectroscopic investigations of oxygen reduction on chalcogen-modified ruthenium catalysts in alkaline media," The Journal of Physical Chemistry C, vol. 115, no. 25, pp. 12650-12664, 2011.

[71] R. Boulatov, "Billion-Year-Old Oxygen Cathode that Actually Works: Respiratory Oxygen Reduction and Its Biomimetic Analogs," in N4-Macrocyclic Metal Complexes, J. H. Zagal, F. Bedioui, and J.-P Dodelet, Eds., p. 1, Springer, Berlin, Germany, 2006.

[72] R. Boulatov, "Metalloporphyrin Catalysts of Oxygen Reduction," in Fuel Cell Catalysis, M. T. M. Koper, Ed., p. 637, John Wiley \& Sons, New York, NY, USA, 2008.

[73] N. Ramaswamy and S. Mukerjee, "Electrocatalysis of oxygen reduction on nonprecious metallic centers at high $\mathrm{pH}$ environments," ECS Transactions, vol. 33, no. 1, pp. 1777-1785, 2010.

[74] K. M. Kadish, E. van Caemelbecke, and R. Royal, "Electrochemistry of metalloporphyrins in nonaqueous media," in The Porphyrin Handbook, K. M. Kadish, K. M. Smith, and R. Guilard, Eds., vol. 8, chapter 55, pp. 1-97, Academic Press, San Diego, Calif, USA, 2000.

[75] M. Teliska, V. S. Murthi, S. Mukerjee, and D. E. Ramaker, "Correlation of water activation, surface properties, and oxygen reduction reactivity of supported $\mathrm{Pt}-\mathrm{M} / \mathrm{C}$ bimetallic electrocatalysts using XAS," Journal of the Electrochemical Society, vol. 152, no. 11, pp. A2159-A2169, 2005.

[76] M. Teliska, W. E. O'Grady, and D. E. Ramaker, "Determination of $\mathrm{O}$ and $\mathrm{OH}$ adsorption sites and coverage in situ on Pt electrodes from Pt L23 X-ray absorption spectroscopy," Journal of Physical Chemistry B, vol. 109, no. 16, pp. 80768084, 2005.

[77] E. A. Lewis, C. U. Segre, and E. S. Smotkin, "Embedded cluster $\triangle$-XANES modeling of adsorption processes on Pt," Electrochimica Acta, vol. 54, no. 28, pp. 7181-7185, 2009.

[78] F. Beck, "The redox mechanism of the chelate-catalysed oxygen cathode," Journal of Applied Electrochemistry, vol. 7, no. 3, pp. 239-245, 1977.

[79] S. R. P. Silva, "Properties of Amorphous Carbon," in Properties of Amorphous Carbon, EMIS Datareviews Series 29, 2003.

[80] Y. J. Cho, H. S. Kim, S. Y. Baik et al., "Selective nitrogen-doping structure of nanosize graphitic layers," Journal of Physical Chemistry C, vol. 115, no. 9, pp. 3737-3744, 2011.

[81] J. R. Hahn and H. Kang, "Vacancy and interstitial defects at graphite surfaces: scanning tunneling microscopic study of the structure, electronic property, and yield for ion-induced defect creation," Physical Review B, vol. 60, no. 8, pp. 6007-6017, 1999.

[82] S. L. Mielke, D. Troya, S. Zhang et al., "The role of vacancy defects and holes in the fracture of carbon nanotubes," Chemical Physics Letters, vol. 390, no. 4-6, pp. 413-420, 2004.

[83] Y. Luo, Y. Heng, X. Dai, W. Chen, and J. Li, "Preparation and photocatalytic ability of highly defective carbon nanotubes," Journal of Solid State Chemistry, vol. 182, no. 9, pp. 2521-2525, 2009.
[84] T. Kondo, T. Suzuki, and J. Nakamura, "Nitrogen doping of graphite for enhancement of durability of supported platinum clusters," Journal of Physical Chemistry Letters, vol. 2, no. 6, pp. 577-580, 2011.

[85] P. Nemes-Incze, Z. Koínya, I. Kiricsi et al., "Mapping of functionalized regions on carbon nanotubes by scanning tunneling microscopy," Journal of Physical Chemistry C, vol. 115, no. 8, pp. 3229-3235, 2011.

[86] A. B. Anderson and R. A. Sidik, "Oxygen Electroreduction on FeII and FeIII Coordinated to N4 Chelates. Reversible Potentials for the Intermediate Steps from Quantum Theory," Journal of Physical Chemistry B, vol. 108, no. 16, pp. 50315035, 2004. 


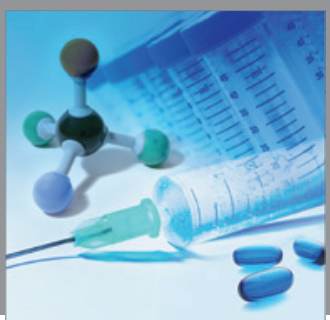

International Journal of

Medicinal Chemistry

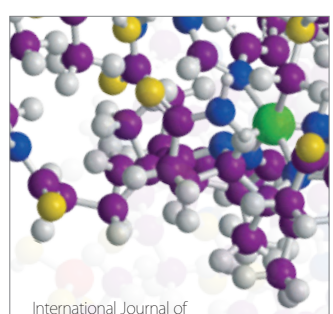

Carbohydrate Chemistry

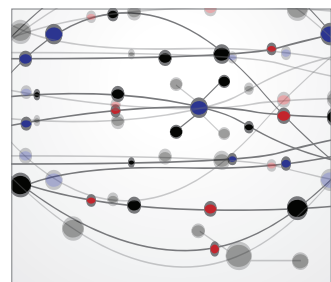

The Scientific World Journal
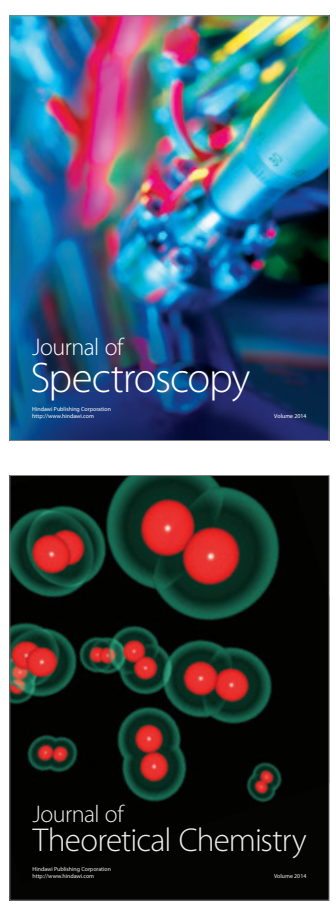


Submit your manuscripts at

http://www.hindawi.com
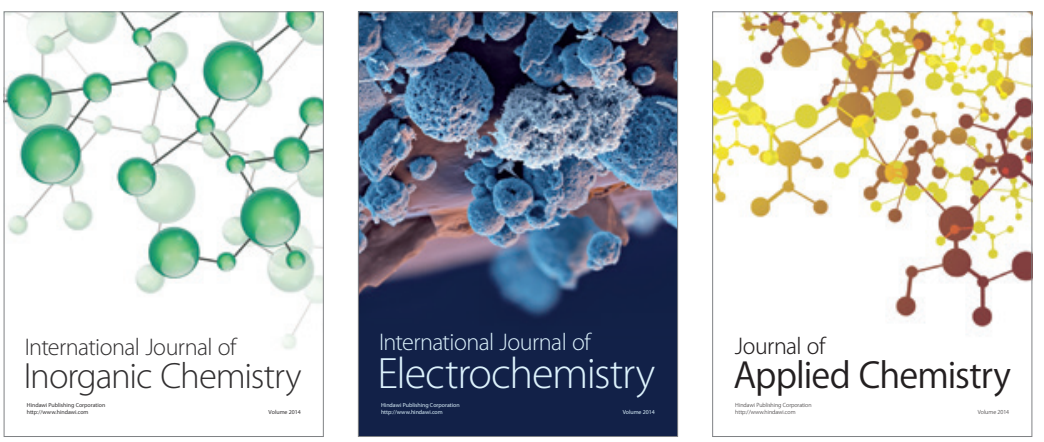

Journal of

Applied Chemistry
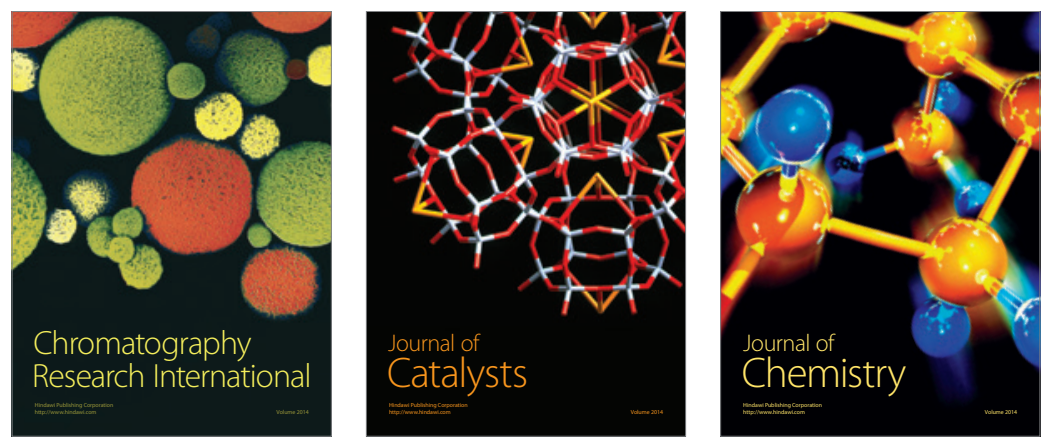
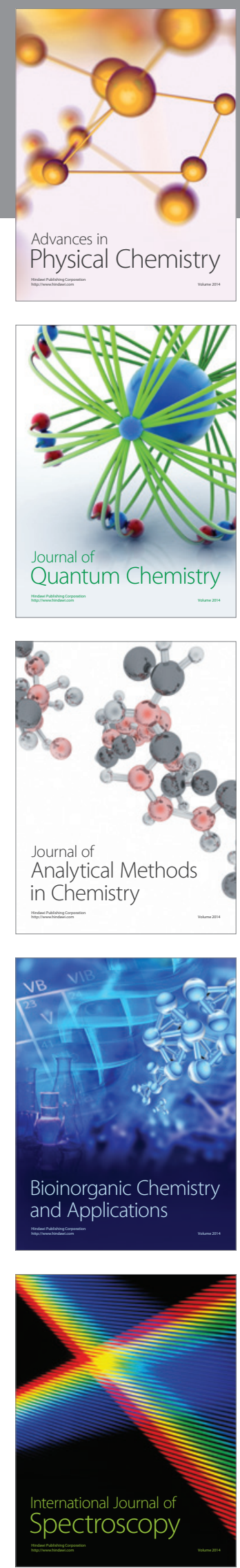